\title{
LA ARQUITECTURA DEL ART DÉCO EN GRECIA. ENTRE EL ECLECTICISMOY EL CLASICISMO MODERNO
}

\author{
Vassilis Colonas \\ Universidad deTesalia, Grecia
}

El Art Déco, corriente artística que se desarrolla en los años 1920 en Francia, sólo se consideró como un estilo a partir de la Exposición Internacional de las Artes Decorativas e Industriales M odernas de París en 1925, donde la decoración triunfó en todas sus formas.

La evolución de esta corriente fue una reacción ante el carácter extremadamente decorativo del Art N ouveau así como su continuación, geometrizada bajo la influencia del cubismo, simplificada por una atracción hacia el neoclasicismo y estrechamente vinculada a la utilización de materiales lujosos.

Notamos, desde la exposición universal de 1900, los gérmenes del declive del Art Nouveau y la reacción que se desencadena en contra de la decoración vegetal curvilínea en exceso tan característica del arte en el anterior decenio.

Esta tendencia se manifiesta a nivel europeo con los W ienner Werkstätte (fundados en 1903 por Hoffman y Moser) y el D eutscheWerbound que asientan las bases de la investigación para los que crearan el nuevo estilo, los cuales sin embargo no están influidos ni por el Bauhaus ni por el De Stijl (no es, por cierto, una casual idad el que no fueran llamadas, estas dos escuelas, a participar en la exposición de 1925).

No obstante son otras las fuentes de inspiración que caracterizan, directa y muy intensamente, la primera fase de evolución de la nueva corriente, hasta la Primera guerra mundial. En París, donde después del Art N ouveau, la tendencia dominante es el retorno a los estilos más antiguos, como el Luis XVI y el Directorio, irrumpen en 1909 los ballets rusos de S. Diaghilev. El despliegue de colores y la riqueza decorativa de los trajes y de los decorados de Léon Bakst conmocionan los círculos artísticos de París y ponen definitivamente fin a las curvas delicadas del Art N ouveau, así como, por supuesto, a cualquier tipo de recidiva. L'Oiseau de feu, La Siesta de un fauno, D afne y Cloe, 
Cleopatra,Tamar son obras presentadas por primera vez en París. Sin olvidar, por encima de todo, Scheherazade con Ida Rubinstein y Nijinsky en los papeles principales. Para numerosos artistas, Serazade fue una fuente de inspiración y para los del Art Deco, una fuente del mismo valor que la arquitectura gótica para los R ománticos o los frescos del Renacimiento para los prerafaelistas.

Los artistas del Art Déco se refieren también al cubismo que rechaza lo decorativo a favor de una visión analítica, realista y objetiva de la forma. Se apropian de sus formas geométricas y geometrizan sus ornamentos, regularizan las líneas a partir de las formas básicas: cilindro, cono, esfera, cubo. El cubismo les enseña también una visión analítica del arte africano, el arte de losAztecas y de los M ayas, fuentes de inspiración muy importantes del Arte. M ás tarde, se añadirán a este repertorio ya muy rico, los nuevos motivos geométricos inspirados en los hallazgos hechos en la tumba deTutankhamón, descubierta en 1923.

Después de la Primera guerra mundial, las nuevas condiciones aceleran la evolución de la nueva corriente que viene a cubrir múltiples necesidades. Europa, al término de la Gran guerra, quiere olvidar. El decenio de 1920 se caracteriza por un optimismo excesivo y la creencia en utopías frente a la dura realidad. Son los años locos del charlestón que quieren borrar la pesadilla de la guerra y enseñar al mundo una nueva cara. N uevas clases sociales se hacen más poderosas, a nivel financiero, una parte de la población, enriquecida por la guerra aspira a despilfarrar su fortuna, deseosa de ocultar su origen humilde u oscuro, busca un nuevo estilo de casa, tiene nuevos gustos, opta con pasión por la nueva corriente.

Existe el encanto del coche, de los viajes transatlánticos, los fabulosos decorados de las superproducciones de $\mathrm{H}$ ollywood, el jazz y los nuevos bailes como el onestep, el black-bottom y el fox-trot dominan, mientras que Josefina Baker electriza a todo París con la R evue N ègre.

Es en este ambiente cuando en 1925 se abre la Exposición Internacional de las Artes Decorativas e Industriales. Consagra el arte «tradicionalista» que se convierte, en el plano internacional, en el Art Déco, estilo lujoso y refinado, en contraste con el «encantador» Art N ouveau. Deja poco espacio a los innovadores como Le Corbusier, quien, desde 1920, en las páginas de la revista Esprit N ouveau expresa nuevos conceptos acerca de la noción de la síntesis y de la construcción.

A pesar de su diversidad y de sus contradicciones, la Exposición de las Artes Decorativas de 1925, según Ivonne Brunhammer, es en definitiva el reflejo exacto de la prodigiosa creatividad de una época que duda entre dos civilizaciones, una heredada del siglo XIX, vinculada al sistema burgués, a la tradición con sus obligaciones, sus lí- 
mites técnicos y estilísticos y no en su dinámica y su ejemplaridad, otra enfocada hacia el futuro y comprometida con la segunda revolución industrial.

El «estilo» que se desprende del conjunto de la exposición de 1925, con sus afirmaciones, sus antagonismos, sus carencias está definitivamente marcado por la fórmula «Art D éco», evocadora de imágenes contradictorias donde el palisandro barnizado coexiste con el tubo niquelado, la «rosa cubista» con la geometría constructivista, la policromía intensa de los Ballets Rusos y de los Fauvistas con la gama apagada de los cubistas y el «Lait de Chaux» de Le Corbusier.

A pesar de todo, nadie puede poner en tela de juicio la univer salidad del Art D éco, el enfoque unificado del diseño total y la imagen de una época impregnada, mediante su pluralismo, del sueño de la generación de la posguerra, porque el Art Déco no sólo representa el lujo de una minoría, sino también la ilusión de la mayoría.

Los años 30 son sinónimos de crisis financiera mundial, paro en constante aumento y subida del partido nacional socialista. Este decenio, en oposición al de los años 1920, privilegia la arquitectura y el diseño de interiores. Las características propias al estilo de los años 30 son la exactitud del dibujo, la transparencia, la luminosidad y la liberación respecto del sentimiento 0 del dogma.

El purismo de los modernos de 1925 era una necesidad precoz. Creó las formas que, muy claramente, establecieron los límites del nuevo estilo. Los elementos que, con anterioridad, hubiera sido difícil considerar como naturales se someten a un proceso de refinado que hace imposible concebirlos de otra manera. Esto se aplica sobre todo a la arquitectura, donde el cubo, forma predilecta del período anterior, empieza a destacar aun más, a integrar la variedad en la estructura y la selección de los materiales, a asociarse a elementos curvilíneos y a transformarse, desde una austera forma de arte, en una cosa nacida de la vida y de la actualidad.

Por otra parte, los partidarios del Art Déco emprenden el mismo camino, también en los años 30: las formas geométricas que daban un aspecto anguloso a los animales, flores y plantas ahora son controladas y se convierten en elementos decorativos. Un mundo nuevo, cuyo progreso tecnológico es imprevisible, elige como símbolo la estética de la máquina y de las líneas aerodinámicas, y la geometría pura se convierte en el furor decorativo de los años 30.

No se puede explicar la simplificación de las formas por la difícil época de la crisis financiera, como creen al gunos, ya que la riqueza de los materiales descubier tos y utilizados desmiente categóricamente esta opinión.

«A nything goes» es una frase a la que Cole Porter puso música y que se convertirá en el lema de los años 1935 a 40; expresará el pluralismo renovado del Art D éco 
en su reconciliación y su interacción con el movimiento moderno, más ampliamente conocido como Depression modern.

El Art Déco es un movimiento internacional, nacido en París en 1925 para conquistar el mundo. A pesar de unas importantes concentraciones en París, Londres 0 Madrid, no tuvo, en Europa, a pesar de ser cuna de la corriente, la repercusión que podía esperarse. Constituyó la elección de cierta vanguardia y sól o fue objeto de una adhesión casi general en las salas de espectáculo y en los espacios de ocio.

El Art Déco también está vinculado a la arquitectura de las nuevas ciudades de África del Norte donde se consolidó como un término medio entre modernismo y eclecticismo en la elección de los promotores y de los arquitectos. Desde Casablanca y O rán hasta El Cairo y A lejandría, el Art Déco lo demuestra y constituye hoy uno de los puntos de referencia de su iconografía.

Especialmente en Alejandría, comparada por ello conTesalónica por al gunos (Ph. D ragoumis, S. T sirkas), la clase de los hombres de negocios y de los propietarios, aprovechando el desarrollo rápido del comercio exterior y de la industria después de la Primera guerra mundial, explotó las necesidades de viviendas e invirtió en el sector de la construcción que conoció un florecimiento inaudito hasta 1938. El Art Déco se utilizó muy ampliamente en los lujosos palacios de la Corniche, en los cines, y también en los inmuebles de la burguesía media de Ibrahimia, de Sidi Gaber y del Sporting.

El Art Déco, y especialmente su evolución posterior en los años 30, más conocida bajo la denominación de Streamline o Depression modern, caracteriza la nueva era en su dinámica, que deja tras sí la crisis financiera y se encamina hacia el futuro con optimismo. Se identifica con el Style International y con el N ew D eal del presidente Roosevelt y constituye después de la guerra, la versión más tangible del «sueño americano» en el mundo entero.

El Art Déco, es introducido en Grecia, en el período de entreguerras, bien por los arquitectos que han estudiado en el extranjero, sobre todo en París y en particular en la École spéciale, o bien mediante revistas de arquitectura de gran difusión que informan a su clientela cosmopolita de las nuevas corrientes arquitecturales. El Art Déco funciona como una innovación en el repertorio estilístico de los arquitectos y, después de una primera fase de coexistencia con el clasicismo y el eclecticismo se impone en los lugares de diversión, tales como los teatros y hoteles, en las instalaciones turísticas de los centros de vacaciones y de las ciudades balneario del período de entreguerras.

El teatro de invierno de M arika Kotopouli en la calle Panepistimiou, conocido con el nombre de «Rex», edificado en 1935-1937 según los planos de L. Bonis yV. Cas- 
sandras, simboliza el Art Deco en A tenas (Fig. 1). También debemos a estos arquitectos la remodelación interior del cine-teatro Pallas (1932), en el complejo de los edificios de la $O$ ficina de Clases Pasivas del Ejército, donde el Art Déco había surgido tímidamente en 1927-28.

El palacio de la 0 ficina de Clases Pasivas del Ejército, fue objeto de un concurso arquitectónico internacional en 1926, ganado por los arquitectosV. Cassandras y Leonidas Bonis, diplomados de la Escuela de Bellas Artes de París. Las obras de construcción se iniciaron en 1928 para concluir en 1939. El palacio de la 0 ficina de Clases Pasivas del Ejército, se compone de tres alas distintas, el edificio que da a la calle Stadiou, el edificio central y el edificio que da a la calle Panepistimiou.

Para el primer edificio de la calle Stadiou, Bonis y Cassandras se apartaron de la facilidad del eclecticismo, que sigue dominando en laA tenas de los años 1920, para orientarse hacia el estilo innovador del Art Déco (Fig. 2). De esta manera, proclaman mediante el tratamiento abstracto de la decoración, las formas geométricas y la utilización de materiales lujosos, su «adhesión» al nuevo estilo que inunda el París de 1925.

El edificio central al berga el cine-teatro Pallas y la sala de baile M axim (Fig. 3). El Pallas, inaugurado en 1932, crea una ruptura con la arquitectura de las salas de cine deAtenas, tanto por sus grandes dimensiones y las estudiadas proporciones de las partes que lo constituyen, como por la elaboración del decorado apacible y discreto de las superficies interiores. La difusión del sonido mejora gracias a las superficies lisas, a los ángulos redondeados, y a las ondulaciones del techo. En una época en la que el «ornamento» está considerado como un «crimen», el Art Déco traduce el furor decorativo del período anterior en unas superficies lisas y pulidas, en formas aerodinámicas, en revestimientos lujosos y detalles refinados.

La selección de los materiales y de los colores y sobre todo la utilización estudiada de la iluminación indirecta desvelan admirablemente el trazado curvilíneo del techo parabolóide. Ninguna línea «dura» se interpone entre el escenario y el espectador; si éste último da la espalda a la pantalla y se encuentra frente a la sala, su mirada no encontrará ni una sola línea vertical, sino un conjunto de líneas curvas formando un equilibrio estético perfecto.

L. BonisyV. Cassandras pudieron disponer de numerosos e importantes modelos, merced a las publicaciones de aquella época y a sus frecuentes viajes a la ciudad donde estudiaron, lo cual les ponía en contacto directo con la actualidad arquitectónica contemporánea. Buscar los orígenes de la manera de concebir los espacios interiores del Pallas nos llevaría hasta París en el cine Gaumont Palace diseñado por Henri Belloc y de construcción reciente en aquel entonces (1931), en particular por la ela- 
boración de los techos parabolóides, de los palcos y la percepción más general de los trazados interiores y de la iluminación.

Influidos por el techo de inspiración inigualada del Palace, estos mismos arquitectos diseñan el espacio interior de la sala de baile M axim (Fig. 4) y posteriormente, volveremos a encontrar este tipo de elaboración de los interiores en Europa y en América en lugares de ocio como el Café de Charles Siclis en los Campos Elíseos en París (1935), y también en los cines de la posguerra como el que proyectó $\mathrm{S}$. Charles Lee en 1947 en Miami.

En el edificio de la calle Panepistimiou inaugurado en 1939, la ausencia de curvas, en contraste con las fachadas del ala de la calle Stadiou, refuerza el carácter monolítico del edificio y lo clasifica entre las muestras representativas del clasicismo moderno en Atenas (Fig. 5). «Clásico» en la disposición de las fachadas, «moderno» en la economía de la decoración, el edificio de la 0 ficina de Clases Pasivas del Ejército, proyecta en la calle Panepistimiou su fachada menos conseguida, austera, petrificada, monótona, constituyendo, respecto de su imagen anterior, una aberración estilística total.

Con los edificios del banco de Grecia (N. Zoumboulidis, 1933-35) y del Tribunal de Cuentas (1934), el de la 0 ficina de Clases Pasivas del Ejército, caracteriza de nuevo el eje de la calle Panepistimiou y determina el regreso de la arquitectura pública a los valores simbólicos del clasicismo. Un regreso muy evidente a las salas de los teatros que L. Bonis yV. Cassandras construirán después de la guerra.

Para la planificación del espacio interior y asociado a la utilización de materiales lujosos (mármol, elementos metálicos cincelados o cromados, maderas especiales, vidrieras), el Art Déco dio excelentes resultados en las entradas y las cajas de escalera de los edificios atenienses en los años 30.

El teatro de verano de M. Kotopouli (D. Pikionis, 1932) y los estudios inspirados de I. Despotopoulos para los cines-teatros de Chios (1927-28), Agrinio (Fig. 6) y D rama (segundo premio del concurso nacional, 1932), los garajes de varias plantas en la calle Kanaris 3 de R. Koutsouris (1936-38), al igual que varios edificios y casas de Tesalónica - como veremos más adelante- se inscriben en la evolución común del Racionalismo y del Art Déco.

Respecto a las ciudades balneario, los Servicios de Extranjeros y de Exposiciones del Ministerio de Economía Nacional en un principio y el O rganismo Helénico del Turismo después de 1930, se dieron cuenta de que «la rápida progresión de la industria hotelera y, a través de ella, la valorización del campo y de las ciudades balneario griegas, la necesidad de mejorar también otras ciudades termales y de costa, abren 
nuevas vías para la obra turística nacional, cuyo éxito pude revelarse como un factor clave para la prosperidad financiera del pueblo».

Gracias a la creación de la O ficina Helénica del Turismo y en el contexto general del desarrollo del turismo tal como se creó, los ingenieros griegos están llamados a cooperar de manera sustancial, tanto con estudios de unidades hoteleras y de centros de hidroterapia, etc. , como con estudios urbanísticos más amplios con el objetivo de rehabilitar ciudades bal neario, como las de M. Delladetsimas para KammenaVourla.

El Art Déco es un lugar común para las ciudades balneario mediterráneas. Aidipsos, KammenaVourla y Loutraki pueden enorgullecerse de hermosísimas muestras arquitectónicas de este estilo de formas puras o influenciadas por el Racionalismo. La primera categoría incluye los centros de hidroterapia de Loutraki (L. Bonis, 1932) y de Kammena Vourda y la segunda los hoteles Radion en Kammena Vourla (1936) (Fig. 7) y Aigli en Aidipsos (Kypr. Biris, 1930), así como los estudios premiados de P. Ka peronis para el establecimiento termal deAidipsos que no se realizaron (Fig. 8).

EnTesalónica, después del gran incendio de 1917 que destruyó la mayor parte del núcleo histórico, se encarga a un comité de siete miembros, dirigido por el arquitecto y urbanista francés Ernest Hébrard, el estudio del nuevo plan urbanístico. En los años 20, la reconstrucción de la zona incendiada y la aplicación del plan Hébrard se materializan, y durante el «gran mandato» del partido de los Liberales (1928-1932), a pesar de las graves consecuencias de la crisis económica mundial en la economía del país, se abre, paraTesalónica y su zona interior, un período de intensa actividad en los sectores del saneamiento, de la infraestructura, de los servicios urbanos y de la modernización de lo ya construido.

En el tercer sector, aparecen los primeros edificios de pisos destinados a albergar sociedades comerciales, oficinas, grandes almacenes, que permiten al barrio conservar los usos urbanos del antiguo centro de negocios de Tesalónica. Sin embargo, invadirán rápidamente todo el centro histórico de la ciudad y, con los primeros inmuebles residenciales que introducen un cambio radical en la estructura de la propiedad - la propiedad horizontal (ley 3741 de 1929)- , pronto caracterizarán las nuevas manzanas del plan Hébrard.

Cierto es que durante los años que siguieron al incendio de 1917, se dio preferencia, en detrimento de las formas innovadoras del Bauhaus, del movimiento moderno 0 incluso del Art Déco, a un nuevo eclecticismo, enriquecido por préstamos morfológicos a estas tendencias contemporáneas y adaptado a la técnica del hormigón armado, que pretende, como práctica arquitectónica y también como metodología, su inserción en la imagen anterior de la ciudad. 
No obstante, la clase burguesa deTesalónica del período entreguerras se apresura en intentar diferenciarse de los estilos arquitectónicos anteriores que otras fuerzas socioeconómicas habían plebiscitado, buscando traducir, mediante el pluralismo de formas que ofrece el Art Déco, sus ambiciones, su reciente fuerza, su «modernidad». Las creaciones que surgen en la zona de los nuevos trazados, y también fuera de lazona incendiada, son originales y reveladoras de la nueva fisionomía «internacional» de la ciudad.

Los casos de arquitecturaA rt D éco son aislados aunque indican su rapidez de extensión en Tesalónica. Arquitectos como Zachariadis [edificio Koffas, 1925 (Figs. 9, 10 y 11), Hotel Ritz, 1924] y N ikopoulos [AImacen de tabaco del monopolio austriaco, 1926 (Fig, 12), edificio Pantazievits, 1928] rechazan las referencias históricas y escogen un nuevo repertorio decorativo que manipulan sin ambigüedad, concediendo prioridad a las formas geométricas -y por ende a los ornamentos esquematizados- a los encuadres lineales y a los colores claros. A esta fase del Art Déco pertenecen la nueva ala del barrio Saul (tienda Fokas) (Fig. 13), el inmueble Dor. Naxiadou (Sal. Pozelli, 1931), el edificio de la plaza Diikitiriou (A. Birdas, 1931) y el inmueble de la calle Aghiou Dimitriou.

El Art Déco aparece en la primera feria internacional de Tesalónica en 1926 (Fig. 14) y es elegido para el diseño de la Puerta principal y la arquitectura de algunos pabellones. El Art Déco se utilizará ampliamente en el recinto de la feria internacional deTesalónica, en los años siguientes y seguirá siendo la elección formal de base de los arquitectos y de los expositores, hasta principios de los años 1950.

En los años treinta, el Art Déco ya no se contenta con la ornamentación en superficie del decenio anterior, sino que se esfuerza, con la estilización de las decoraciones con líneas quebradas o curvas, en subrayar los elementos de estructura, en dar forma a los coronamientos de los edificios y en ofrecer un ligero relieve a las fachadas donde las superficies planas empiezan a combinarse con superficies curvas.

El Art Déco evoluciona de acuerdo con el movimiento moderno, en el que el cubismo de los racionalistas se vuelve menos rígido y las for mas geométricas de la decoración del Art Déco se convierten ellas mismas en ornamento, transformándose en elementos de estructura tales como balcones, parapetos, marcos de aberturas, formación de ángulos, coronamientos, tragaluces, agrupados a menudo en ejes centrales o laterales.

EnTesalónica, esta convergencia se inclina a favor del Art Déco combinado con las formas aerodinámicas del Streamline o Depression modern, denominación preponderante en Estados U nidos de la arquitectura que surgió como consecuencia de la 
crisis de 1929. Pronto se convierte en modelo para la arquitectura internacional del decenio de los años 1930 y, enTesalónica, constituye una feliz innovación en la elección arquitectónica de los propietarios y de los arquitectos, teniendo como característica principal la introducción de la curva en las fachadas y los planos (Fig. 15). No debemos olvidar que casi todos los arquitectos de la ciudad estudiaron en el extranjero y que se encuentran más cercanos a la actual idad internacional que sus colegas de Atenas que, al contrario, permanecen apegados a los principios del Racionalismo y del clasicismo, abstracto o moderno.

En los inmuebles de este decenio donde la propiedad horizontal se convirtió en una verdadera institución, la utilización recurrente de la planta-modelo es evidente e influye notablemente en la construcción de las fachadas. De nuevo, constituirá la característica de las manzanas del plan Hébrard, con importantes concentraciones en los sectores cuarto y quinto, y fuera de la zona incendiada, a lo largo de las calles Egnatia y Prinkipos N ikolaou (hoy Alexandrou Slovou).

Debemos mencionar a titulo indicativo los inmuebles I. M andalidis ( $E$. M odiano, 1931) (Fig. 16), K. Exharopoulos (Tzonis-Palaiologos, 1933), G. Malakis-G, Papamanolis (G. Malakis, 1930) (Fig. 17), (Koniordos G. M anousos, 1934) (Figs. 18 y 19) en la costa, los inmueblesVafiadis (G. Manousos) (Fig. 20) y G. T sakiris (G: manousos, 1940) en la calle Egnatia, K. Toliadouris (G. M anousos, 1934) en la calle Prinkipos Nikolaou, el inmueble de los hermanosAfias (M. Roubens, 1935) (Fig. 21) en la calle Antigonidon, el de G. Guinis en la calle M akenzie King (Tzonis-Palaiologos, 1935) (Fig. 22), y el edificio de la calle Delliou (G. Manousos, 1936).

Se incluyen, en el movimiento Depression Modern que guía la arquitectura internacional del decenio de 1930, la nueva estación ferroviaria deTesalónica (K leinschmidt-Jordan, 1939) (Fig. 23), los almacenes de tabaco, el cine Elíseos, así como numerosas viviendas particulares del antiguo barrio de los Campos, al este de la ciudad (Fig. 24).

El Art Déco sigue siendo un movimiento internacional. Q uizá no tuvo la difusión del arte moderno, quizá tampoco se interesaron por él los historiadores de la arquitectura, sin embargo, la breve duración de su resplandor (1925-1950) lo protegió de la hiper-simplificación y de la degradación que afectaron al arte moderno en la arquitectura de los años 70 y 80 . H oy en día, cuando estamos en la época de la nostal gia de las corrientes arquitectónicas del período de entreguerras, el Art Déco, convertido en materia protegida, sigue seduciendo. 



\section{L'ARCHITECTURE DE L'ART DÉCO \\ EN GRĖCE. ENTRE ÉCLECTISME ET \\ CLASSICISME MODERNE}

Vassilis Colonas

Université deThessalie, Grèce

L'Art D éco, courant artistique qui se développe dans les années 1920 en France, n'a été considéré comme un style qu'à partir de l'Exposition Internationale desArts D écoratifs et Industriels Modernes de Paris en 1925, qui a vu la décoration triompher dans toutes ses formes.

L'évolution de ce courant a été une réaction au caractère extrêmement décoratif de l'Art N ouveau en même temps que sa continuation, géométrisée sous I' influence du cubisme, simplifiée par un penchant pour le néo-classicisme et étroitement liée à l'utilisation des matériaux precieux.

On perçoit, dès l'exposition universelle de 1900, les germes du déclin de l'Art nouveau et la réaction qui déferle contre la décoration végétale curviligne àl'excès si caractéristique de l'art dans la décennie précédente.

Cette tendance s'exprime au niveau européen par lesW ienner Werkstätte (fondés en 1903 par Hoffman et Moser) et le Deutsche Werkbound qui mettent les bases de la recherche pour ceux qui créeront le nouveau style, lesquels pourtant ne sont influencés ni par le Bauhaus ni par le De Stijl (ce n'est d'ailleurs pas par hasard que ces deux écoles n' ont pas été appelées à prendre part à l'exposition de 1925).

Cependant autres sont les sources d'inspiration qui caractérisent, directement et très intensément, la première phase d'évolution du nouveau courant, jusqu'à la première guerre mondiale. A Paris, où après I'A rt N ouveau, la tendance dominante est au retour aux styles plus anciens, comme le Louis XVI et le Directoire, débarquent en 1909 les ballets russes de S. Diaghilev. L'étalage des couleurs et la richesse décorative des costumes et des décors de Léon Bakst bouleversent les cercles artistiques de Paris et mettent définitivement fin aux courbes délicates de l'Art nouveau, comme d'ailleurs à tout type de récidive. L'O iseau de feu, I'Après-midi d'un faune, Daphné et Chloé, Cléôpatre,Thamar sont des œuvres présentées pour la première fois à Paris. Sans oublier, 
par-dessus tout, Shérazade avec Ida Rubinstein et Nijinsky dans les premiers rôles. Pour de nombreux artistes, Shérazade a été une source d'inspiration et pour ceux de l'Art déco, une source de même val eur que l'architecture gothique pour les Romantiques ou les fresques de la Renaissance pour les pro-Raphaëlistes.

Les artistes de l'Art Déco se référent égal ement au cubisme qui refuse le décoratif pour une vision analytique, réaliste et objective de la forme. Ils lui empruntent ses formes géométriques et géométrisent leurs ornements, régularisent les lignesà partir des formes de base: cylindre, cône, sphère, cube. Le cubisme leur enseigne aussi une vision analytique sur l'art africain, I'art desAztèques et des M aya, sources d'inspiration de l'Art très importantes. $A$ ce répertoire déjà riche, s'ajouteront plus tard les nouveaux motifs géométriques inspirés par les trouvailles de la tombe de Toutankhamon, découverte en 1923.

A près la Première guerre mondiale, les conditions nouvelles accélèrent l'évolution du nouveau courant qui vient couvrir de multiples besoins.

L'Europe, à la sortie de la Grande guerre, veut oublier. La décennie de 1920 se caractérise par un optimisme excessif et la croyance en des utopies contre la dure réa lité. Ce sont les années folles du charleston qui veulent effacer le cauchemar de la guerre et montrer au monde un visage nouveau. De nouvelles classes montent en puissance, financièrement parlant, une part de la population, enrichie par la guerre, aspire à gaspiller sa fortune, désireuse d'en cacher l'origine humble ou obscure, elle cherche un nouveau type de maison, elle a de nouveaux goûts, elle opte avec passion pour le nouveau courant.

II y a le charme de la voiture, des voyages outre-atlantique, les décors fabuleux des superproductions de H ollywood, le jazz et les nouvelles danses comme le onestep, le black-bottom et le fox-trot dominent, tandis que Joséphine Baker électrifie le tout Paris avec la Revue N ègre.

C'est dans cette atmosphère que s' ouvre en 1925 l'Exposition Inter nationale desArts D écoratifs et Industriels. Elle consacre l'art «traditionaliste» qui devient, sur le plan international, l'Art déco, style luxueux et raffiné, en opposition avec le «ravissant»Art nouveau . Elle fait une faible part aux novateurs comme Le Corbusier, qui, depuis 1920, dans les pages de la revue Esprit N ouveau exprime de nouvelles conceptions de la notion de la synthèse et de la construction.

Dans sa diversité et ses contradictions, I'Exposition des Arts Décoratifs de 1925, selonY vonne Brunhammer, est en définitive l'exact reflet de la créativité prodigieuse d' une époque qui hésite entre deux civilisations, I'une héritée du XIX e siècle, attachée au système bourgeois, à la tradition dans ses contraintes, ses limites techniques 
et stylistiques et non pas dans sa dynamique et son exemplarité, l' autre tournée vers I' avenir et engagée dans la deuxième revolution industrielle.

Le «style» qui se dégage de l'ensemble de l'exposition de 1925, avec ses affirmations, ses antagonismes, ses manques est définitivement marqué par la formule «Art Déco», évocatrice d' images contradictoires où le palissadre verni voisine avec le tube nickelé, la «rose cubiste» avec la géometrie constructiviste, la polychromie intense des Ball lets R usses et des Fauves avec la gamme éteinte des Cubistes et le «Lait de Chaux» de le Corbusier.

Malgré tout, nul ne peut mettre en doute l'universalité de l'Art déco, l'approche unifiée du total design et l'image d'une époque imprégnée, à travers le pluralisme de l'Art déco, du rêve de la génération d'après-guerre, parce que l'Art déco n'est pas juste le luxe d'une minorité, mais aussi l'illusion de la majorité.

Les années 30 sont synonymes de crise financière mondiale, chômage en constante hausse et montée du parti national-socialiste. Cette décennie, à l'opposé de celle de 1920, privilégie l'architecture et le design intérieur. Les propriétés propres au style des années 30 sont l'exactitude du dessin, la transparence, la luminosité, et la libération par rapport au sentiment ou au dogme.

Le purisme des modernes de 1925 était une nécessité précoce. II a créé les formes qui ont, très clairement, posé les limites du nouveau style. Les éléments qu'il aurait été, précédemment, difficile de considérer comme naturels passent par une procédure de raffinage qui les rend impossible à concevoir autrement. Ceci s' applique principalement à l'architecture, où le cube, forme de prédilection de la période précédente, commence à se détacher davantage, à intégrer la variété dans la structure et la sélection des matériaux, à s'allier à des éléments curvilignes et à se transformer, d'une forme $d^{\prime}$ art austère, en une chose issue de la vie et de l'actualité.

De l' autre côté, les partisans de l'Art déco s'engagent dans cette même voie, égal ement dans les années 30: les formes géométriques qui donnaient un aspect anguleux aux animaux, fleurs et plantes sont maintenant contrôlées et deviennent ellesmêmes décorations. Un monde nouveau, au progrès technologique imprévisible, prend pour symbole l'esthétique de la machine et des lignes aérodynamiques, et la géométrie pure devient la fureur décorative des années30.

La simplification des formes ne s'explique pas par l'époque difficile de la crise financière, comme certains le croient, la richesse des matériaux découverts et utilisés démentant catégoriquement cette opinion.

«Anything goes», c'est une phrase mise en musique par Cole Porter qui sera la devise de années 1935 à 40 et qui exprimera le pluralisme renouvelé de l'Art déco 
dans sa réconciliation et son interaction avec le mouvement moderne, plus largement connu comme Depression modern.

L'Art déco est un mouvement international, parti de Paris en 1925 pour conquérir le monde. Malgré de fortes concentrations à Paris, Londres ou Madrid, il n'a pas eu en Europe, pourtant berceau du courant, la répercussion qu' on pouvait attendre. II a constitué le choix d'une certaine avant-garde et n'a fait I'objet d'une adhésion quasi générale que dans les salles de spectacle et les espaces de loisir.

L'Art déco est également lié àl'architecture des nouvelles villes d'A frique du Nord où il s' est affirmé comme un moyen terme entre modernisme et éclectisme dans le choix des commanditaires et des architectes. De Casablanca et de 0 ran, au Caire et àA lexandrie, I'Art déco en atteste et constitue aujourd'hui un des points de référence de leur iconographie.

A Alexandrie notamment, comparée en cela àThessal oniki par certains (Ph. D ragoumis, S. T sirkas), la classe des négociants et des propriétaires, profitant de l'essor rapide du commerce extérieur et de l'industrie après la première guerre mondiale, a exploité les besoins en logements et investi dans le secteur du bâtiment qui a connu une floraison inouïe jusqu' en 1938. L'Art déco a été utilisé très largement dans les palais luxueux de la Corniche, dans les cinémas, mais aussi dans les immeubles de la moyenne bourgeoisie de Ibrahimia, de Sidi Gaber et du Sporting.

L'Art déco, et principalement sa post-évolution des années 30, plus connue sous l'appellation Streamline ou Depression modern, caractérise l'ère nouvelle dans sa dynamique, qui laisse la crise financière derrière elle et se tourne versl' avenir avec optimisme. II est identifié au Style international et au New Deal du président Roosevelt et constitue, après la guerre, la version la plus tangible du «rêve américain» aux quatre coins de la terre.

L'Art déco est introduit en Grèce, dans I'entre-deux-guerres, soit par les architectes qui ont étudié à l'étranger, surtout à Paris et en particulier à l'École spéciale, soit au travers de revues d' architecture de grande diffusion qui informent leur clientèle cosmopolite des nouveaux courants architecturaux. L'Art déco fonctionne comme une innovation dans le réper toire stylistique des architectes et, après une première phase de coexistence avec le classicisme et l'éclectisme, il prend le pas dans les lieux de divertissement comme les théâtres et hôtels, et dans les installations touristiques des lieux de vacances et villes thermales de l'entre-deux-guerres.

Le théâtre d'hiver de Marika Kotopouli dans la rue Panepistimiou, connu sous le nom «R ex», bâti en 1935-1937 d' après des plans de L. Bonis etV. Cassandras, symbolise I'Art déco àA thènes (Fig. 1). 0 n doit aussi à ces architectes I' aménagement 
intérieur du cinéma-théâtre Pallas (1932), dans le complexe des bâtiments de la Caisse de Retraite de l'Armée, où l'Art déco avait fait une timide apparition en 1927-28.

Le palais de la Caisse de Retraite de l'Armée, a fait l'objet d'un concours architectural international en 1926, remporté par les architectesV. Cassandras et Leonidas Bonis, diplômés de l'École des Beaux-Arts de Paris. Les travaux de construction démarrent en 1928 pour s'achever en 1939.

Le palais de la Caisse de Retraite de l'Armée, inclut trois ailes distinctes, le bâtiment donnant sur la rue Stadiou, le bâtiment central et le bâtiment donnant sur la rue Panepistimiou.

Pour le premier bâtiment de la rue Stadiou, Bonis et C assandras se sont écartés de la facilité de l'éclectisme, qui reste dominant dans l'Athènes des années 1920, pour s' orienter vers le style novateur de l'Art déco (Fig. 2). Ils affichent ainsi, par le traitement abstractif de la décoration, les formes géométriques et l'utilisation de matériaux luxueux, leur «adhésion» au nouveau style qui inonde Paris de 1925.

Le bâtiment central abrite le cinéma-théâtre Pallas et le Dancing M axim (Fig. 3). Le Pallas, inauguré en 1932, crée une rupture d' avec I'architecture des salles de cinéma d'Athènes, tant par ses grandes dimensions et les proportions étudiées des parties qui le constituent, que par l'élaboration du décor calme et discret des surfaces intérieures. La diffusion du son se trouve améliorée par les surfaces unies, les angles arrondis et les ondulations du plafond. A une époque où I' «ornement» est considéré comme un «crime», l'Art déco transcrit la fureur décorative de la période précédente en des surfaces lisses et polies, des formes aérodynamiques, des revêtements luxueux et des détails raffinés.

La sélection des matériaux et des couleurs et surtout I'utilisation étudiée de l'éclairage indirect révèlent à merveille le tracé curviligne du plafond paraboloïde. Aucune ligne «dure» ne s' interpose entre la scène et le spectateur; si ce dernier tourne le dos àl'écran et fait face à la salle, son regard ne rencontrera pas une ligne verticale, mais un ensemble de lignes courbes en équilibre esthétique parfait.

$L$. Bonis etV. Cassandras ont eu à leur disposition de nombreux et d'importants modèles, grâce aux publications de l'époque et par leurs fréquents voyages dans la ville de leurs études qui les mettaient en contact direct avec l'actual ité architecturale contemporaine. Chercher les origines du mode de conception des espaces intérieurs du Pallas nous entraînerait à Paris au cinéma Gaumont Palace dessiné par Henri Belloc et de construction alors récente (1931), en particulier par l'élaboration des plafonds paraboloïdes, des balcons et la perception plus générale des tracés intérieurs et de l'éclairage. 
Influencés par le plafond d'inspiration inégalée du Palace, ces mêmes architectes dessinent l'espace intérieur du dancing Maxim (Fig. 4) et l'on retrouvera ultérieurement ce mode d'élaboration des intérieurs en Europe et en Amérique dans des lieux de divertissement comme le café de Charles Siclis aux Champs Élysées à Paris (1935), mais aussi dans des cinémas d' après-guerre, comme celui que $S$. Charles Lee a conçu en 1947 à Miami.

Dans le bâtiment de la rue Panepistimiou inauguré en 1939, I'absence de courbes, en opposition aux façades de l'aile de la rue Stadiou, renforce le caractère monolithique du bâtiment et le range dans les échantillons représentatifs du classicisme moderne à A thènes (Fig. 5). «Classique» par l'ordonnance des façades, «moderne» par l'économie du décor, le bâtiment de la Caisse de Retraite de l'A rmée, projette sur la rue Panepistimiou sa façade la moins réussie, austère, figée, monotone, en aberration stylistique complète par rapport à son image précédente.

Avec les bâtiments de la banque de Grèce (N. Zoumboulidis, 1933-35) et de la Cour des Comptes (1934), celui de la Caisse de Retraite de l'Armée, caractérise de nouveau l'axe de la rue Panepistimiou et marque le retour de l'architecture publique aux val eurs symboliques du classicisme. Un retour fort-evident aux salles des théâtres que L. Bonis etV. Cassandras vont construire après la guerre.

Pour la planification de l'espace intérieur et associé à l'utilisation de matériaux luxueux (marbre, éléments métalliques martelés ou chromés, des bois spéciaux, vitrages en cristal), I'Art-D éco a donné d'excellents résultats dans les halls d'entrée et les cages d'escalier des immeubles athéniens dans les années 30.

Le théâtre d'été de M. Kotopouli (D. Pikionis, 1932) et les études inspirées de I. Despotopoulos pour les cinémas-théâtres de Chios (1927-28), Agrinio (Fig. 6) et D rama (deuxième prix du concours national, 1932), les garages à plusieurs étages dans la rue Kanaris 3 de R. Koutsouris (1936-38), de même que plusieurs immeubles et maisons deThessal oniki - comme on le verra par la suite- s'inscrivent dans le cheminement commun du modernisme et de l'Art déco.

En ce qui concerne les villes thermales, les Services des Etrangers et des Expositions du M inistère de l'Économie Nationale initialement et l'O rganisme Hellénique du Tourisme après 1930, ont pris conscience que «la progression rapide de l'industrie hôtelière et par celle-ci la mise en valeur des campagnes et des villes thermales grecques, la nécessité d'améliorer aussi d'autres villes d'eau et de bord de mer ouvrent de nouvelles voies dans l'oeuvre touristique nationale, dont la réussite peut s'avérer un facteur clé pour la prospérité financière du peuple».

Avec la fondation de l'O ffice Hellénique duTourisme et dans le contexte gé- 
néral du développement touristique tel qu'il est créé, les ingénieurs grecs sont appelés à coopérer de façon substantielle, tant par des études d' unités hôtelières et de centres d'hydrothérapie, etc., que par des études d'urbanisme plus larges visant la réhabilitation des villes thermales, comme celles de M. Delladetsimas pour Kammena Vourla.

L'Art déco est un lieu commun pour les villes thermales méditerranéennes. Aidipsos, KammenaVourla et Loutraki peuvent s' enorgueillir de très beaux échantillons d'architecture de ce style dans des formes pures ou influencées par le modernisme. La première catégor ie compte les centres d'hydrothérapie de Loutraki (L. Bonis, 1932) et de KammenaVourla et la deuxième les hôtels Radion à KammenaVourla (1936) (Fig. 7) et Aigli àAidipsos (Kypr. Biris, 1930), de même que les études primées de P. Kaperonis pour l'établissement thermal d'Aidipsos qui n'ont pas été réalisées (Fig. 8).

A Thessaloniki, après le grand incendie de 1917 qui a détruit la plus grande partie du noyau historique, un comité de sept membres, dirigé par l'architecte et urbaniste français Ernest Hébrard, est chargé de l'étude du nouveau plan. Dans les années 20, la reconstruction de la zone incendiée et l'application du plan Hébrard se concrétisent, et pendant le «grand mandat» du parti des Libéraux (1928-1932), malgré les lourdes conséquences de la crise économique mondiale sur l'économie du pays, s'ouvre, pour Thessaloniki et son arrière-pays, une période d'intense activité dans les secteurs de l' assainissement, de l'infrastructure, des services urbains et de la modernisation du bâti.

Dans le troisième secteur, les premiers bâtiments à étages destinés à abriter des sociétés de commerce, des bureaux, des grands magasins, permettant au quartier de conserver les usages fonciers de l'ancien centre des affaires de Thessal oniki, font leur apparition. Rapidement toutefois, ils envahiront tout le centre historique de la ville et, avec les premiers immeubles d'habitation qui introduisent un changement radical dans l' institution de la propriété - la propriété horizontale (loi 3741 de 1929 sur la propriété par étage), ils caractériseront bientôt les nouveaux ilôts du plan Hébrard.

II est un fait que pendant les années qui ont suivi I'incendie de 1917, la préférence est donnée, au détriment des formes novatrices du Bauhaus, du mouvement moderne ou même encore de l'Art déco, à un nouvel éclectisme, enrichi d'emprunts morphologiques de ces tendances contemporaines et adapté à la technique du béton armé, qui ambitionne, en tant que pratique architecturale mais aussi comme méthodologie, d'être inséré dans l'image précédente de la ville.

Pourtant, la classe bourgeoise de Thessaloniki de l'entre-deux-guerres ne tarde pas à tenter de se différencier des styles architecturaux précédents que d'autres 
forces socio-économiques avaient plébiscités, cherchant à traduire, au travers du pluralisme des formes qu' offre l'Art déco, ses ambitions, sa force récente, son «modernisme». Les compositions qui émergent sur le front des nouveaux tracés, mais aussi en dehors de la zone incendiée, sont originales et révélatrices du nouveau visage «international» de la ville.

Les cas d'architecture Art déco sont isolés, mais indicatifs de sa vitesse de propagation àThessaloniki. Des architectes comme Zachariadis [immeuble Koffas, 1925 (Figs. 9, 10 et 11), Hôtel Ritz, 1924] et Nikopoulos [Entrepôt de tabac du monopole autrichien, 1926 (Figs. 12), immeuble Pantazievits 1928] rejettent les références historiques et choisissent un nouveau répertoire décoratif qu'ils manipulent sans ambiguité, en accordant la priorité aux formes géométriques - et par extension aux décors schématisés- aux encadrements linéaires et aux couleurs claires. A ppartiennent à cette phase de l'Art déco la nouvelle aile de la Cité Saul (magasin Fokas) (Fig. 13), I'immeuble Dor. Naxiadou (Sal. Pozelli, 1931), le bâtiment de la place Diikitiriou (A. Birdas, 1931) et l'immeuble de la rue Aghiou Dimitriou.

L'Art déco apparaît à la première foire inter nationale deThessal oniki en 1926 (Fig. 14) et il est adopté pour la conception de la Porte d'honneur et l'architecture de certains pavillons. Dans l'espace de la foire internationale de Thessaloniki en particulier, I'Art déco sera utilisé très largement dans les années suivantes et il restera le choix formel de base des architectes et des exposants, jusqu' au début des années 1950.

Dans les années trente, l'Art déco ne se contente plus de l'ornementation en surface de la décennie précédente, mais s' efforce, par la stylisation des décors en lignes brisées ou courbes, de souligner les éléments de structure, de donner forme aux couronnements des bâtiments et d'imprimer un léger relief aux façades où les surfaces planes commencent à se combiner à des surfaces courbes.

L'Art déco évolue de concert avec le mouvement moderne, où le cubisme des modernes se fait moins rigide et les formes géométriques des décorations de l'Art déco deviennent elles-mêmes décorations, se transformant en éléments de structure, tels balcons, parapets, cadres d'ouvertures, formation d' angles, couronnements, lucarnes, souvent groupés sur des axes centraux ou latéraux.

A Thessaloniki, cette convergence penche en faveur de l'Art déco combiné aux formes aérodynamiques du Streamline ou Depression modern, appellation dominante aux États-U nis de l'architecture qui a suivi la crise de 1929. Bientôt il donne le ton à l'architecture internationale de la décennie de 1930 et, àT hessaloniki, il constitue une innovation heureuse dans le choix architectural des propriétaires et des architectes, avec pour caractéristique principale l'introduction de la courbe au niveau des 
façades et des plans (Fig. 15). N'oublions pas que presque tous les architectes de la ville ont étudié à l'étranger et sont plus proches de l'actualité internationale que leurs confrères d'Athènes qui, àl'opposé, restent attachés aux principes du modernisme et du classicisme, abstrait ou moderne.

Dans les immeubles de cette décennie où la propriété horizontale est devenue une véritable institution, la récurrence de l'étage-type est évidente et influence sensiblement la formation des façades. Elle caractérisera de nouveau les îlots du plan Hébrard, avec de grosses concentrations dans les quatrième et cinquième secteurs, et, en dehors de la zone incendiée, le long des rues Egnatia et Prinkipos Nikolaou (aujourd' hui Alexandrou Slovou).

Mentionnons àtitre indicatif les immeubles I. Mandalidis (E. Modiano, 1931) (Fig. 16), K. Exarhopoulos (T zonis-Palaiologos, 1933), G. M alakis-G. Papamanolis (G. Malakis, 1930) (Fig. 17), Koniordos (G. M anousos, 1934) (Figs. 18 et 19) sur le front de mer, les immeubles Vafiadis (G. Manousos) (Fig. 20) et G. Tsakiris (G. Manousos, 1940) dans la rue Egnatia, K. Toliadouris (G. Manousos, 1934) dans la rue Prinkipos Nikolaou, I'immeuble des frères Afias (M. Roubens, 1935) (Fig. 21) dans la rue Antigonidon, celui de G. Guinis dans la rue Makenzie King (Tzonis-Palaiologos, 1935) (Fig. 22), et le bâtiment de la rue Delliou (G. M anousos, 1936).

Dans le mouvement Depression M odern qui mène l'architecture internationale de la décennie de 1930, s'insèrent la nouvelle gare ferroviaire de Thessal oniki (K leinschmidt-Jordan, 1939) (Fig. 23), les entrepôts de tabac, le cinéma Élysées, de même que de nombreuses habitations particulières de I' ancien quartier des $C$ ampagnes, àl' est de la ville (Fig, 24).

L'Art déco est resté un mouvement international. II n'a peut-être pas eu la diffusion du moderne, les historiens de l'architecture ne s'y sont peut-être pas non plus particulièrement intéressés, mais la durée brève de son rayonnement (1925-1950) I'a protégé de l'hyper-simplification et de l'avilissement qu'a connus le moderne dans l'architecture des années 70 et 80 . Aujourd' hui où l'époque est à la nostal gie des courants architecturaux de l'entre-guerres, l'Art déco, devenu objet de protection, continue de séduire... 



\section{BIBLIO GRAFÍA - BIBLIO GRAPHIE}

Bayer, P., Art D eco Architecture, Thames \& Hudson, London 1992.

Brunhammer,Y., Le style 1925, Payot, Paris 1987 (N ouv. éd.).

Brunhammer,Y., «Les années 1920-1939. Entre deux guerres mondiales, entre deux expositions internationale». Les réalismes. (Catalogue d' exposition), Centre G. Pompidou, Paris 1981, pp. 344-353.

Cabanne, P., EncyclodédieArt Déco, Somogy, Paris 1986.

Colonas, V., «L' architectureArt-Déco àT hessal oniki de l' entre-deux-guerres», Actes du colloque Ville et architecture néoclassiques, Ecole d' Architecture, Thessaloniki 1983, pp. 248-258 (en grec).

Colonas, V., «L' architectureArt Déco et son évolution àT hessaloniki», The world of Buildings, No 5, Athènes, Juin 1994, pp. 40-52 (en grec).

Klein, D., All color book of Art Deco, 0 ctopous, Hong Kong 1974.

Ragon, M., H istoire mondiale de l' architecture et de l' urbanisme modernes, t. 2. Castermann, Paris 1972.

Veronesi, G., Style 1925, A. Krafft, Lausanne 1968. 



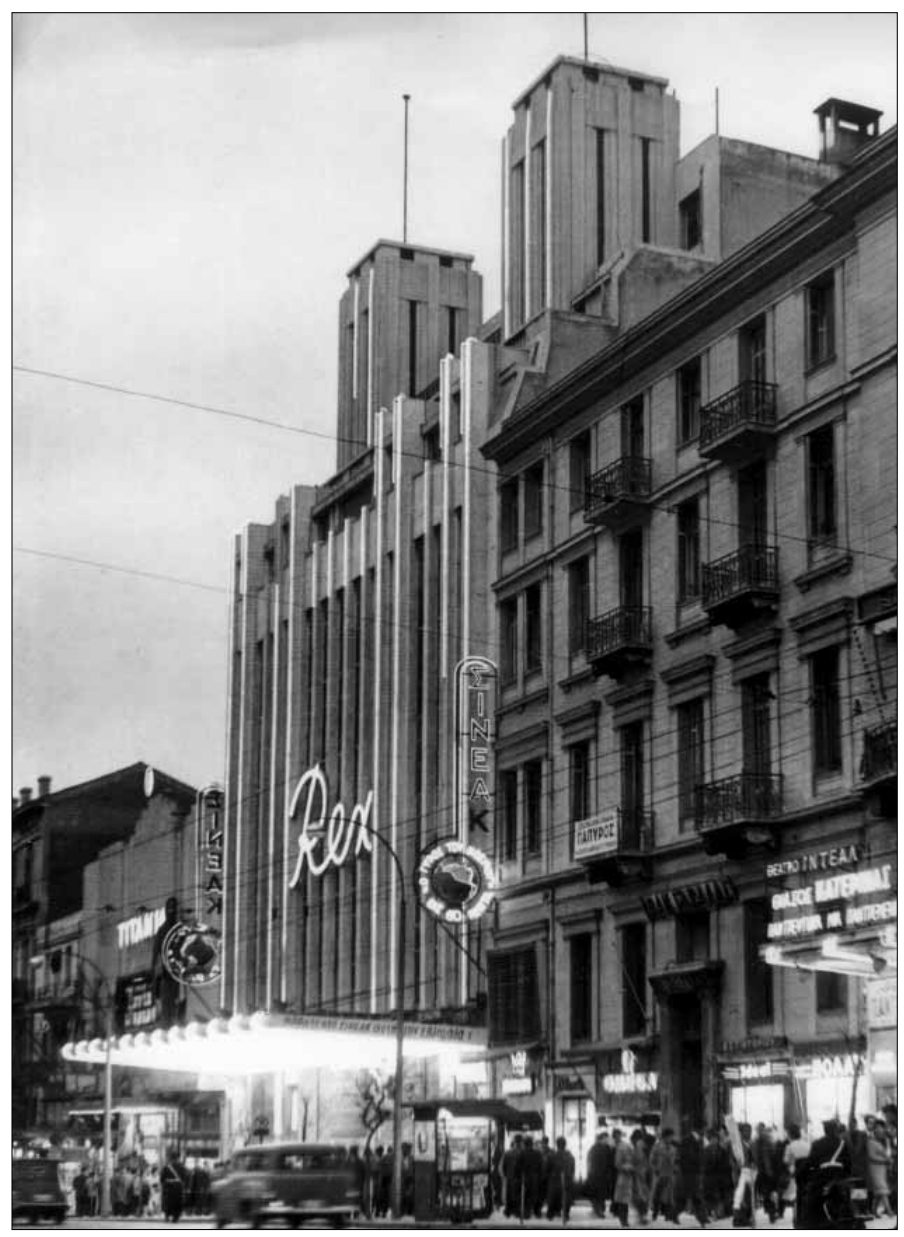

Fig. 1. Athènes. Le cinémathéâtre «Rex», (L. Bonis -

V. Cassandras, 1935-1937). Archives du musée du Théâtre. 
Fig. 2. Athènes. Le palais de la Caisse de Retraite de l'Armée, le bâtiment donnant sur la rue Stadiou (L. Bonis V. Cassandras, 1928). Archive M. Adami.

Fig. 3. Athènes. Le cinéma théâtre «Pallas» (L. Bonis V. Cassandras, 1932). Archives photograpfiques du musée Benakis.
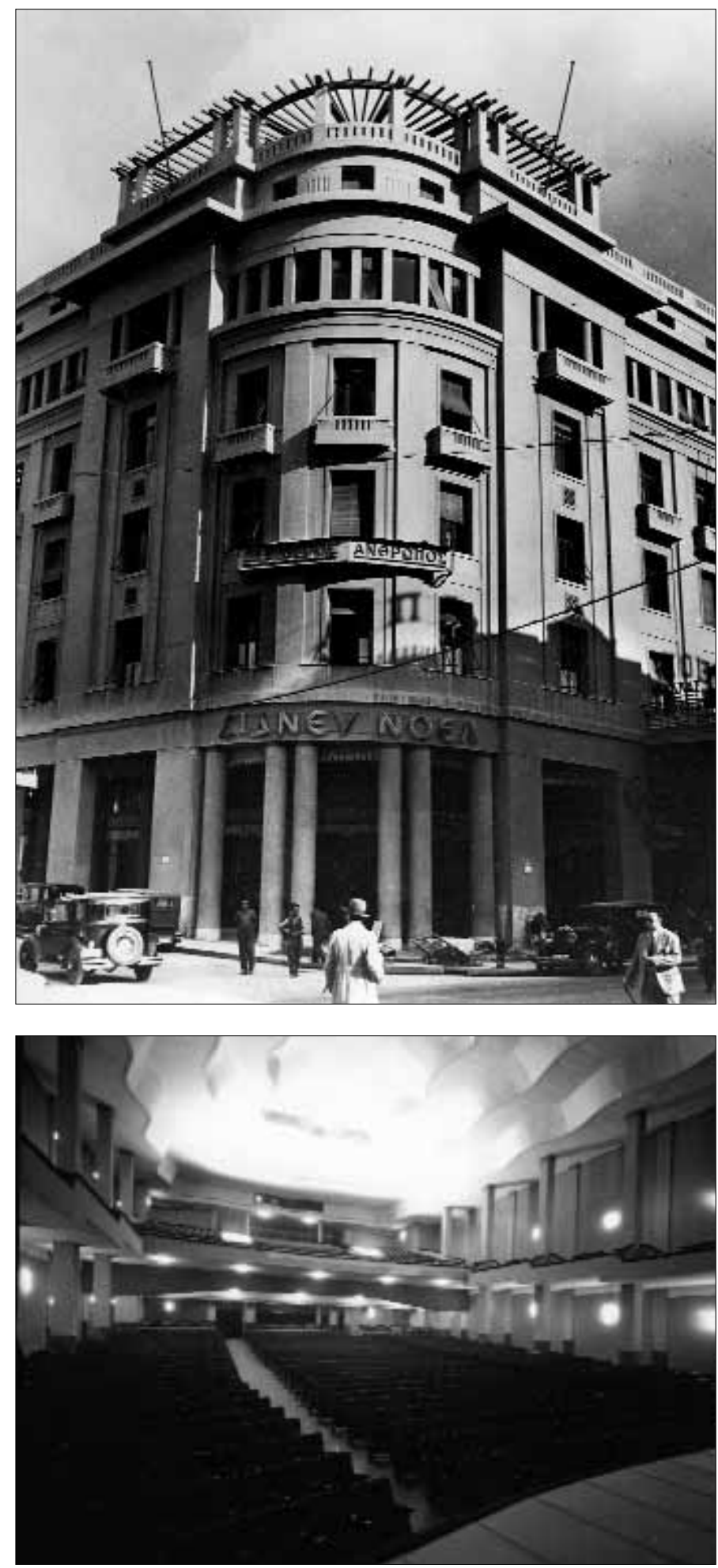

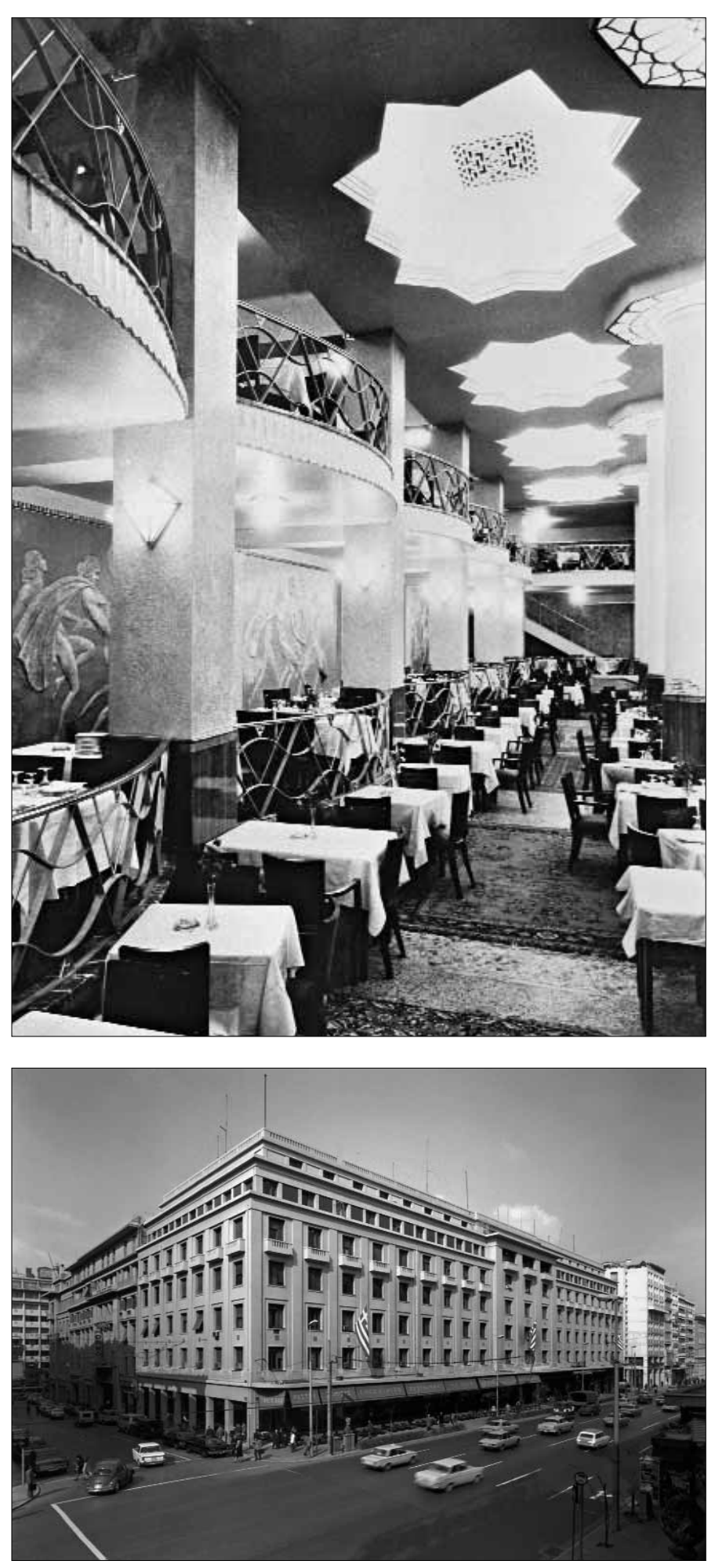

Fig. 4. Athènes. Le Dancing «M axim» (L. Bonis -

V. Cassandras, 1937). Archive E. Fessa.
Fig. 5. Athènes. Le palais de la Caisse de Retraite de I'Armée, le bâtiment donnant sur la rue Panepistimiou (L. Bonis - V. Cassandras, 1939). Photo de G. Kalapodas. 
Fig. 6. Projet pour un cinéma-théâtre à Agrinio, non réalisé (I. D espotopoulos, c. 1930). Archives photograpfiques du musée Benakis.

Fig. 7. L' hôtel Radion à KammenaVourla (1936). ArchiveV. Colonas.
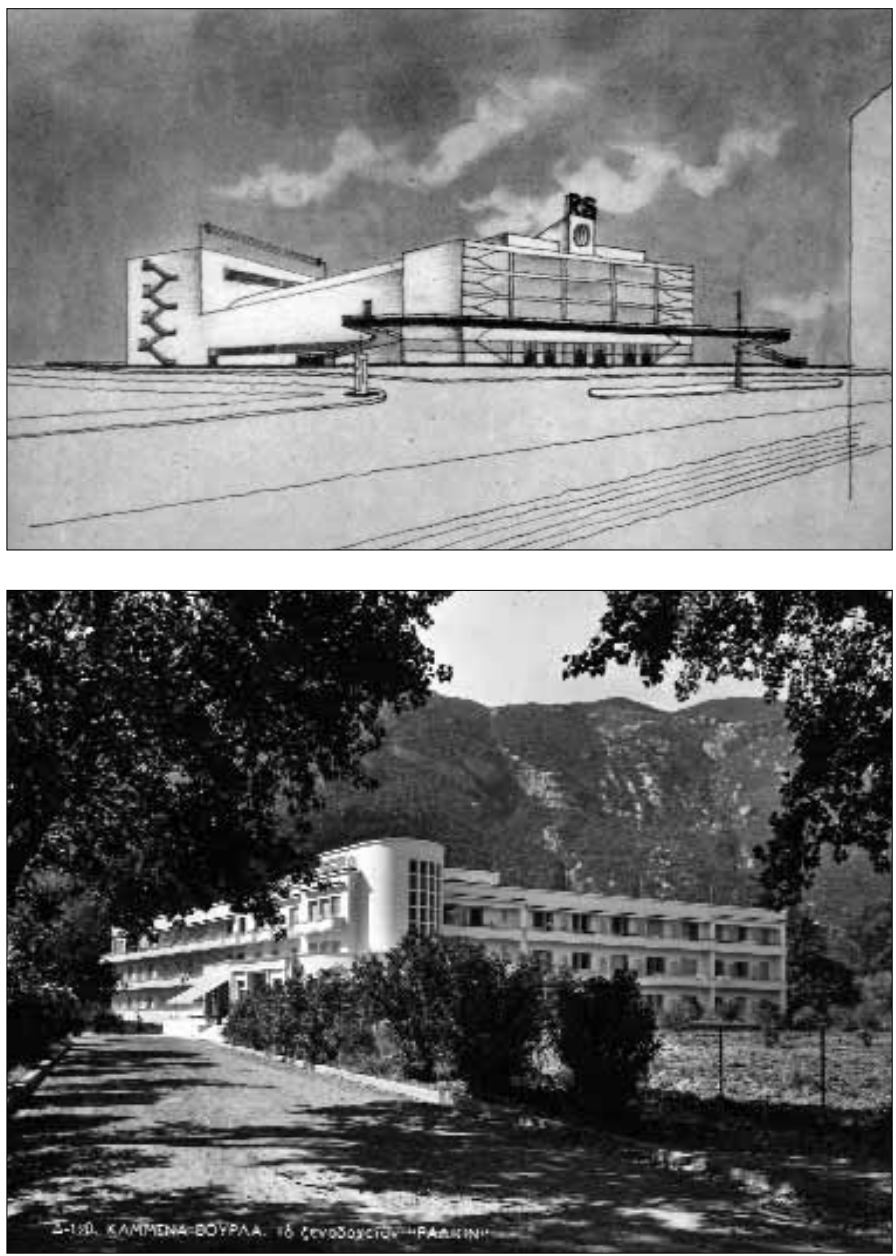

Fig. 8. Vue perspective du ler prix du concours pour I'établissement thermal d'Aidipsos, non réalisée (P. Kaperonis, 1937). Technika Chronika, Août 1937, p. 712.

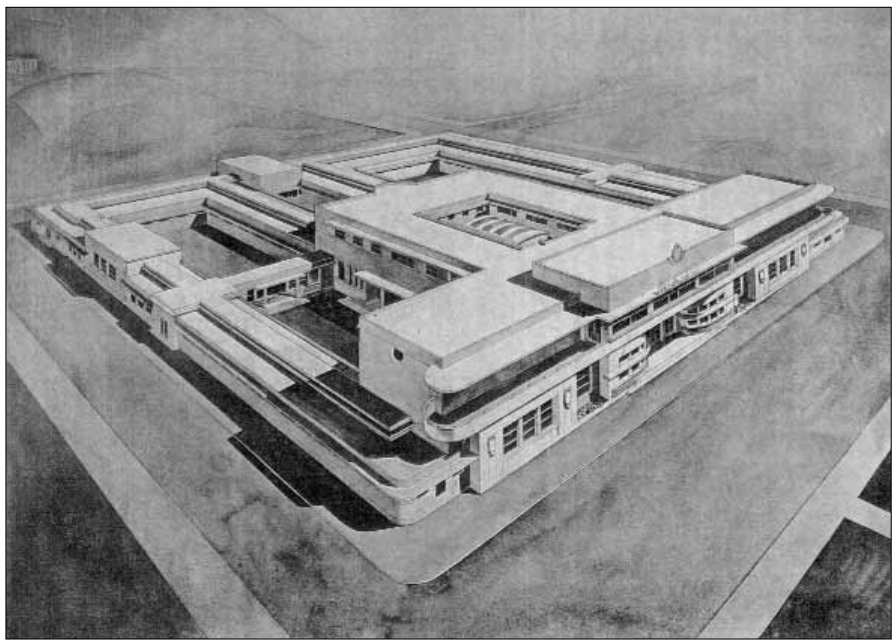




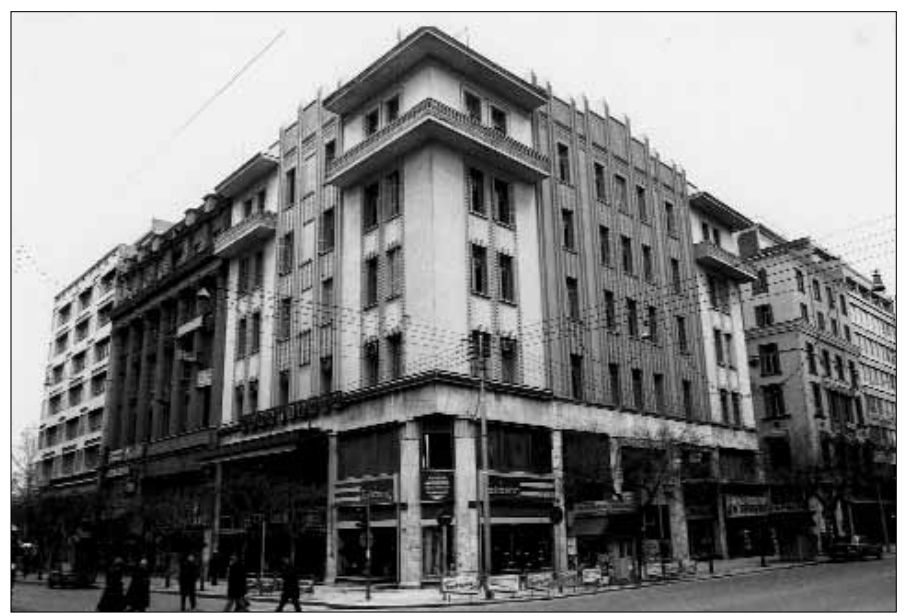

Fig. 9. Thessaloniki.

L'immeuble Koffas, rue

Tsimiski (I. Zachariadis, 1925).

Photo deV. Colonas.

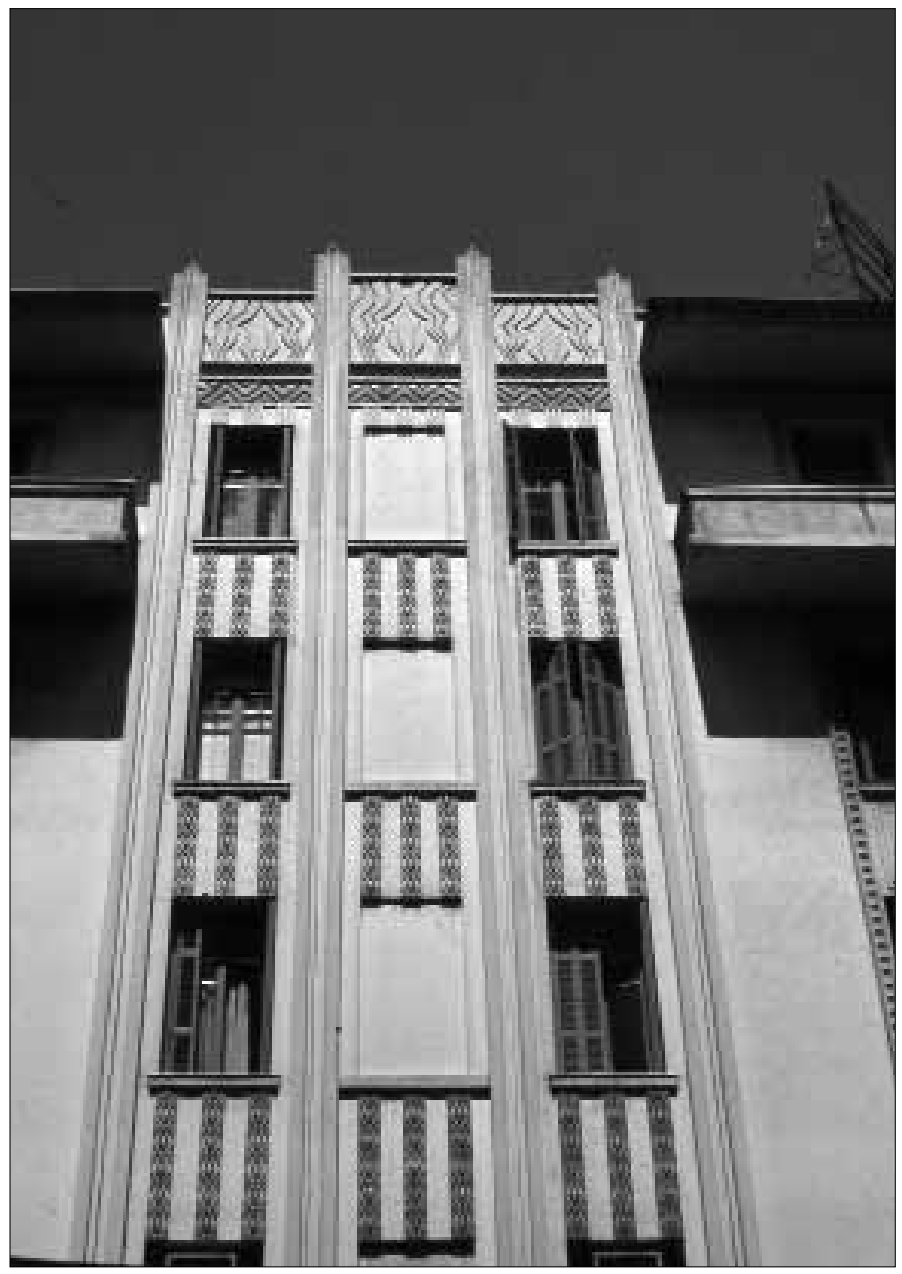

Fig. 10. Thessal oniki.

L'immeuble Koffas, detail de

la façade (I. Zachariadis, 1925).

Photo deV. Colonas. 
Fig. 11. Thessal oniki. Le magasin de Columbia au rez-de-chaussée de l'immeuble Koffas (I. Zachariadis, 1925). ArchiveV. Colonas.

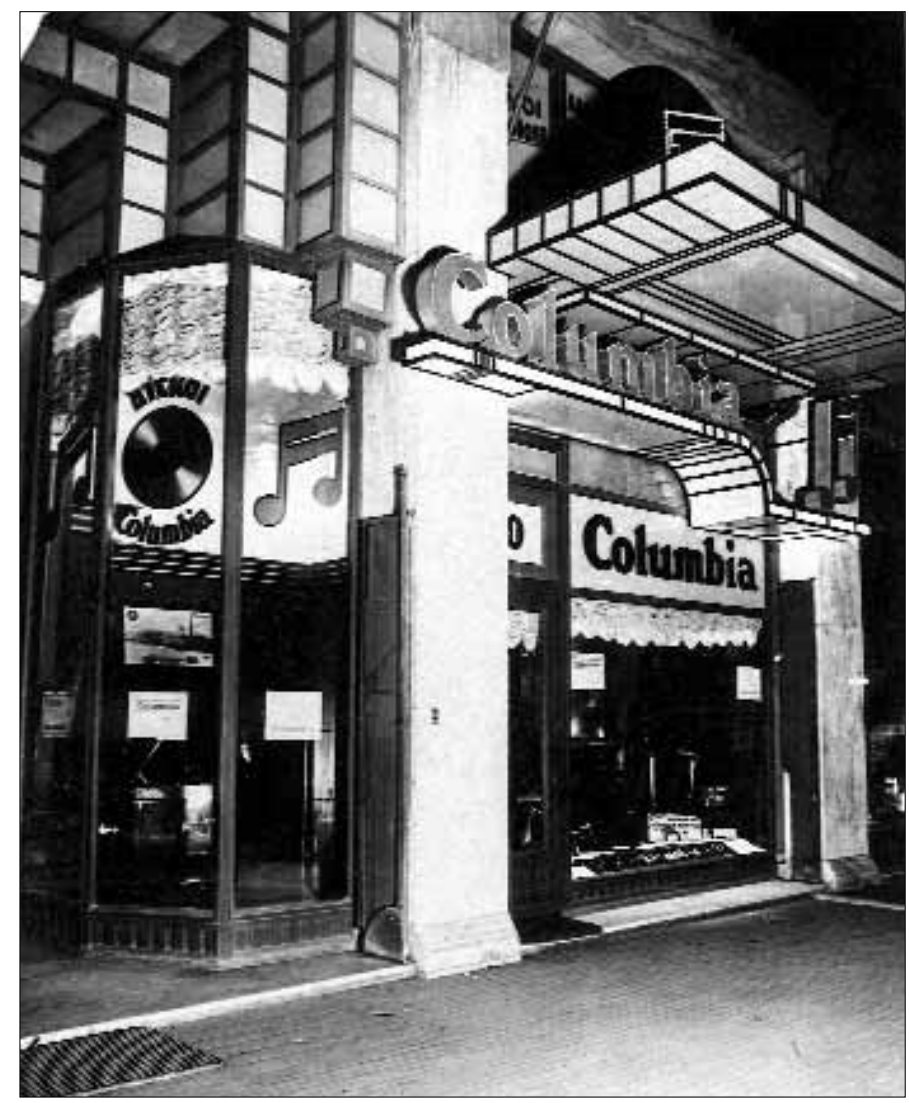

Fig. 12. Thessal oniki. L'entrepôt de tabac du monopole autrichien, rue Tsimiski (A. Nikopoulos, 1926). Photo deV. Colonas.

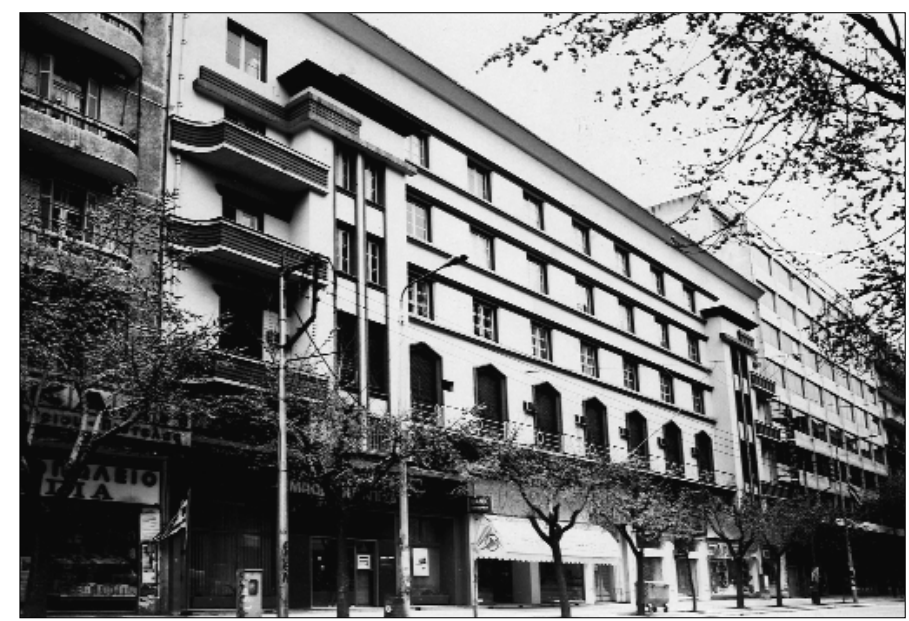




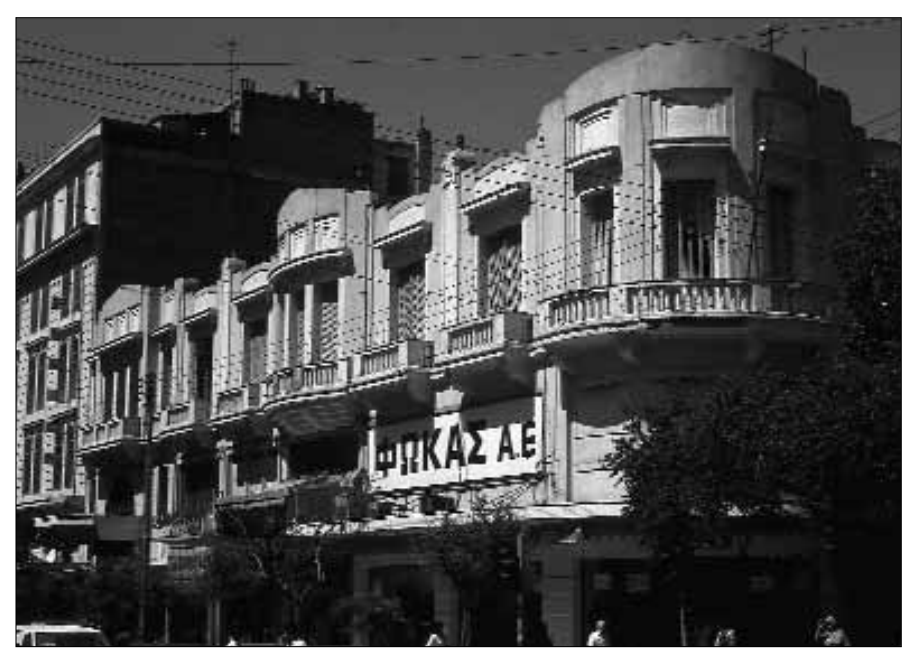

Fig. 13. Thessaloniki. Les grands magasins Fokas, rue Venizelos (c. 1935). Photo de V. Colonas.

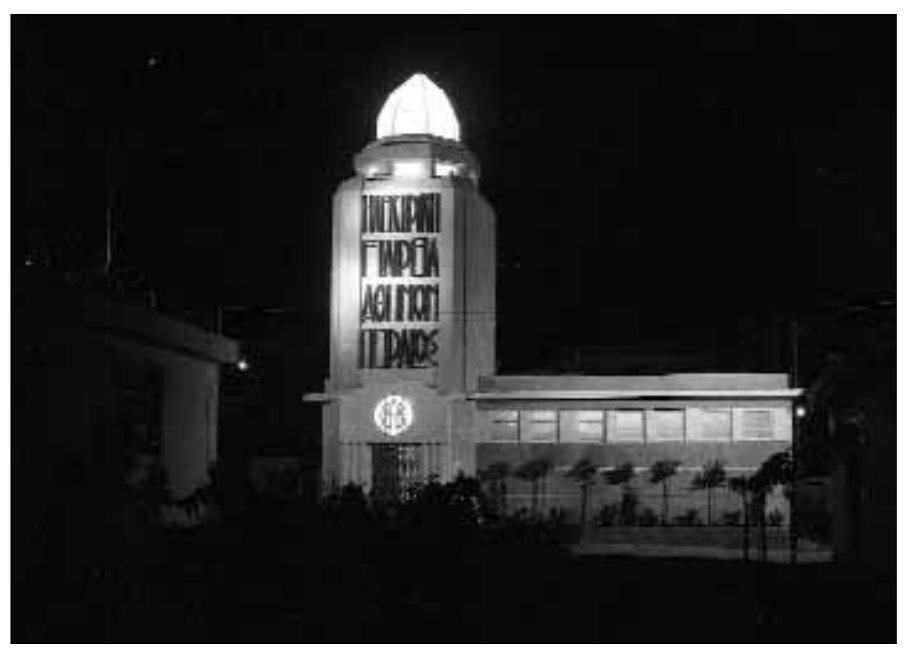

Fig. 14. Foire Internationale deThessaloniki. Le pavillon de la Société Electrique d'Athènes et Pirée (E. Lazaridis, C. 1928). Photo de G. Lykidis, archive G. M egas.

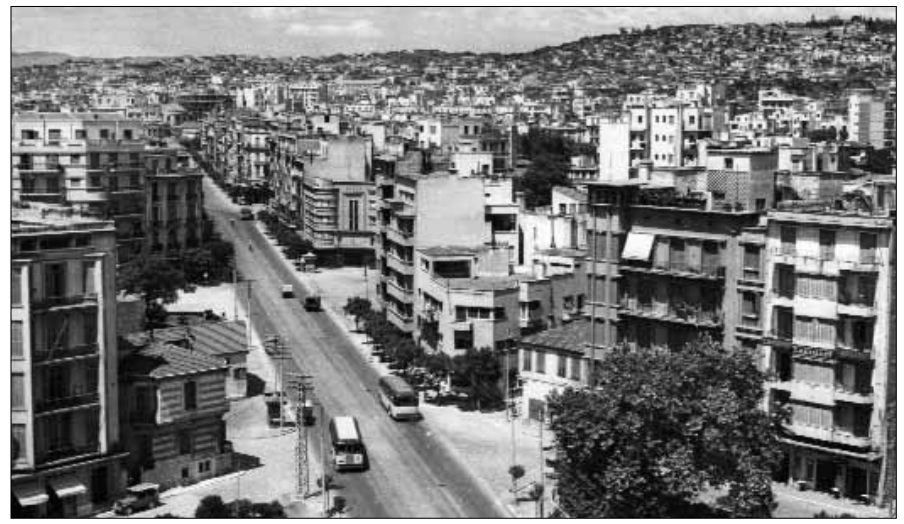

Fig. 15. Thessaloniki. La rue P. M ela en 1951. Au centre, le cinéma Élysées (L. Zoidis, 1930). Photo de G. Lykidis, archive G. Megas. 
Fig. 16. Thessaloniki. Les immeubles I. M andalidis

(E. Modiano, 1931) et G. Malakis-G. Papamanolis (G. Malakis, 1930) sur le front de mer. Photo deV. Mittas.

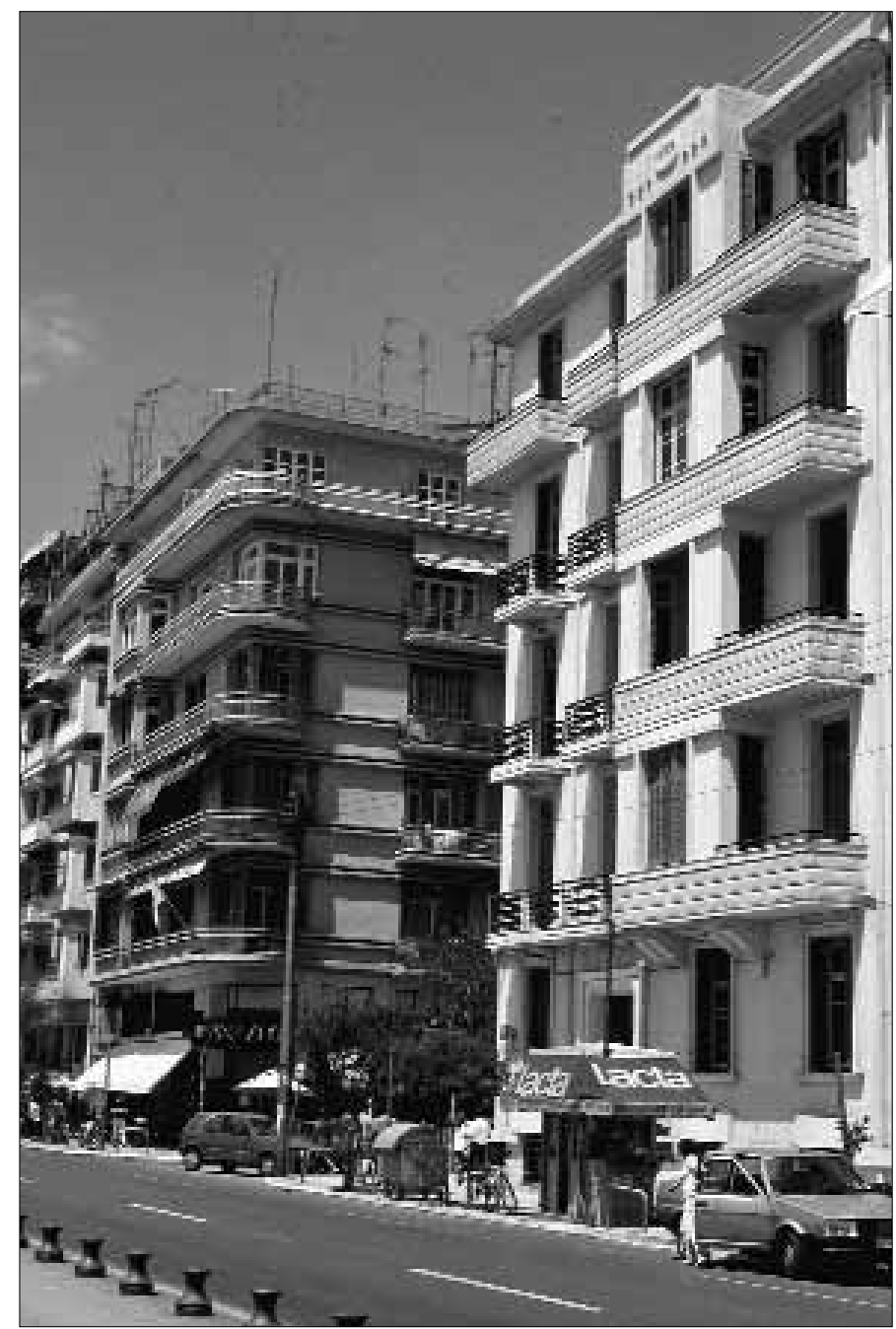




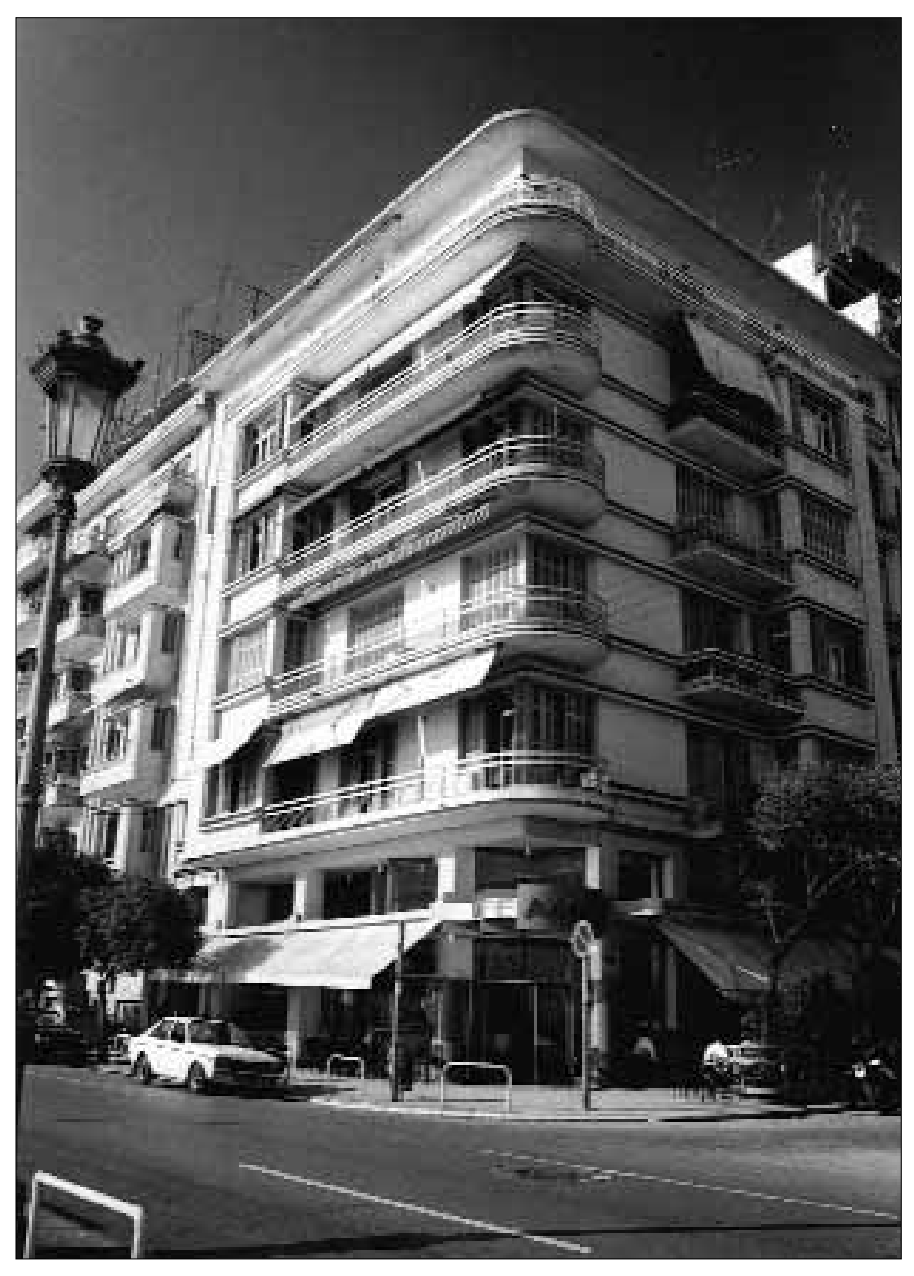

Fig. 17. Thessaloniki.

L'immeuble G. M alakis -

G. Papamanolis (G. Malakis, 1930) sur le front de mer. Photo deV. Mittas. 
Fig. 18. Thessal oniki. L'immeuble Koniordos

(G. Manousos, 1934) sur le front de mer. Photo de V. Mittas.

Fig. 19. Thessal oniki. L'immeuble Koniordos, I'entrée (G. Manoussos, 1934). Photo deV. Colonas.
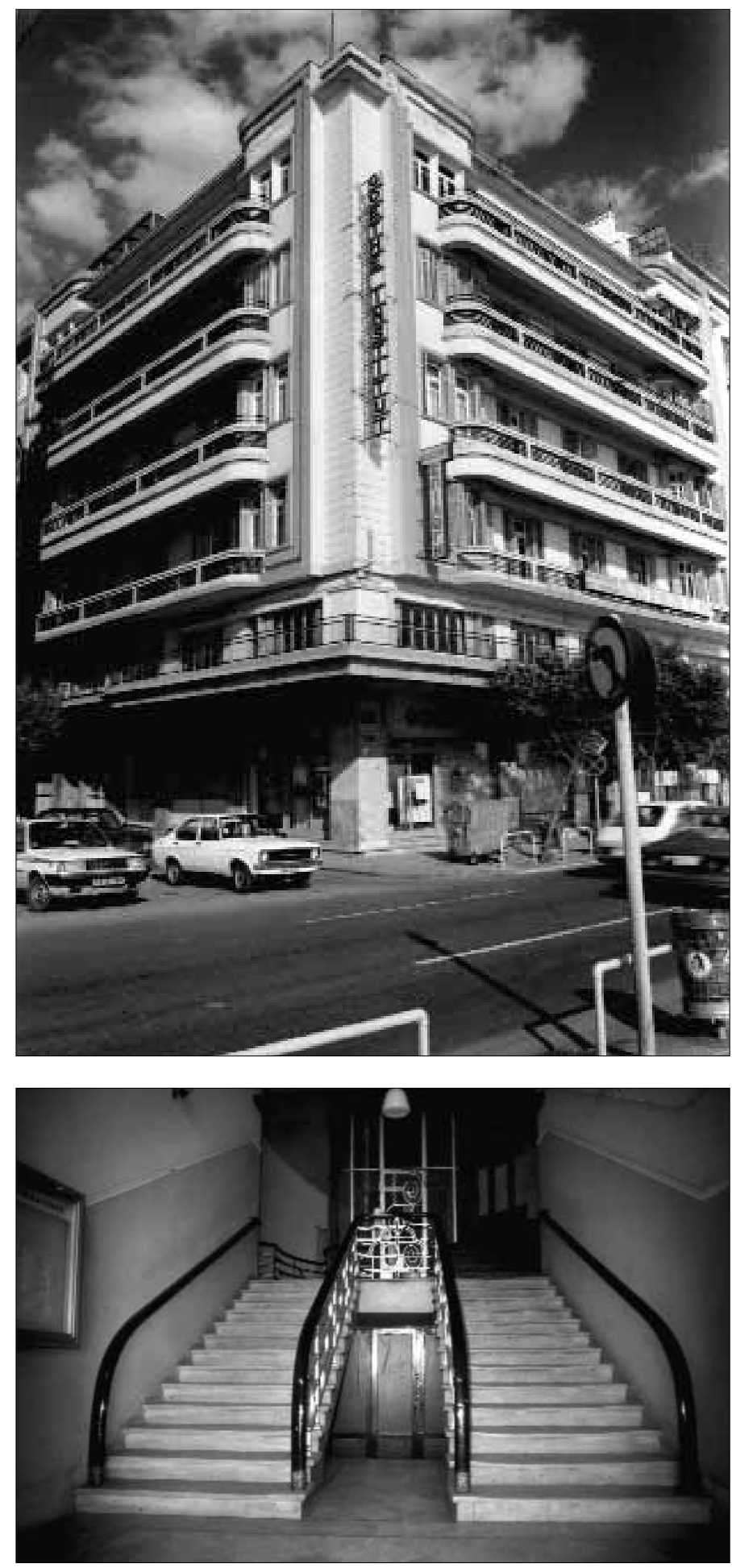


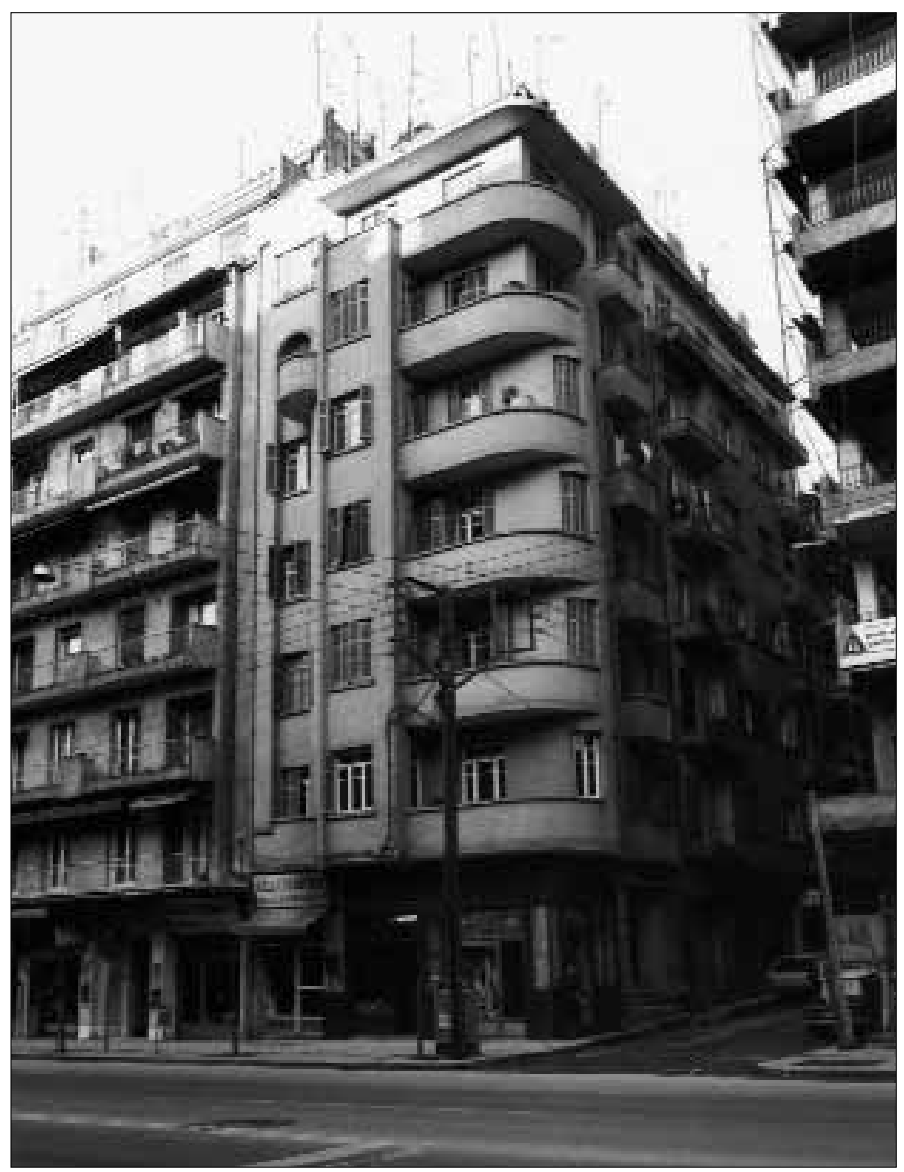

Fig. 20. Thessal oniki.

L'immeubleVafiadis, rue

Egnatia (G. Manousos). Photo deV. Colonas. 
Fig. 21. Thessal oniki. L'immeuble des frères Afias, rue Antigonidon (M. Roubens, 1935). Photo deV. Colonas.

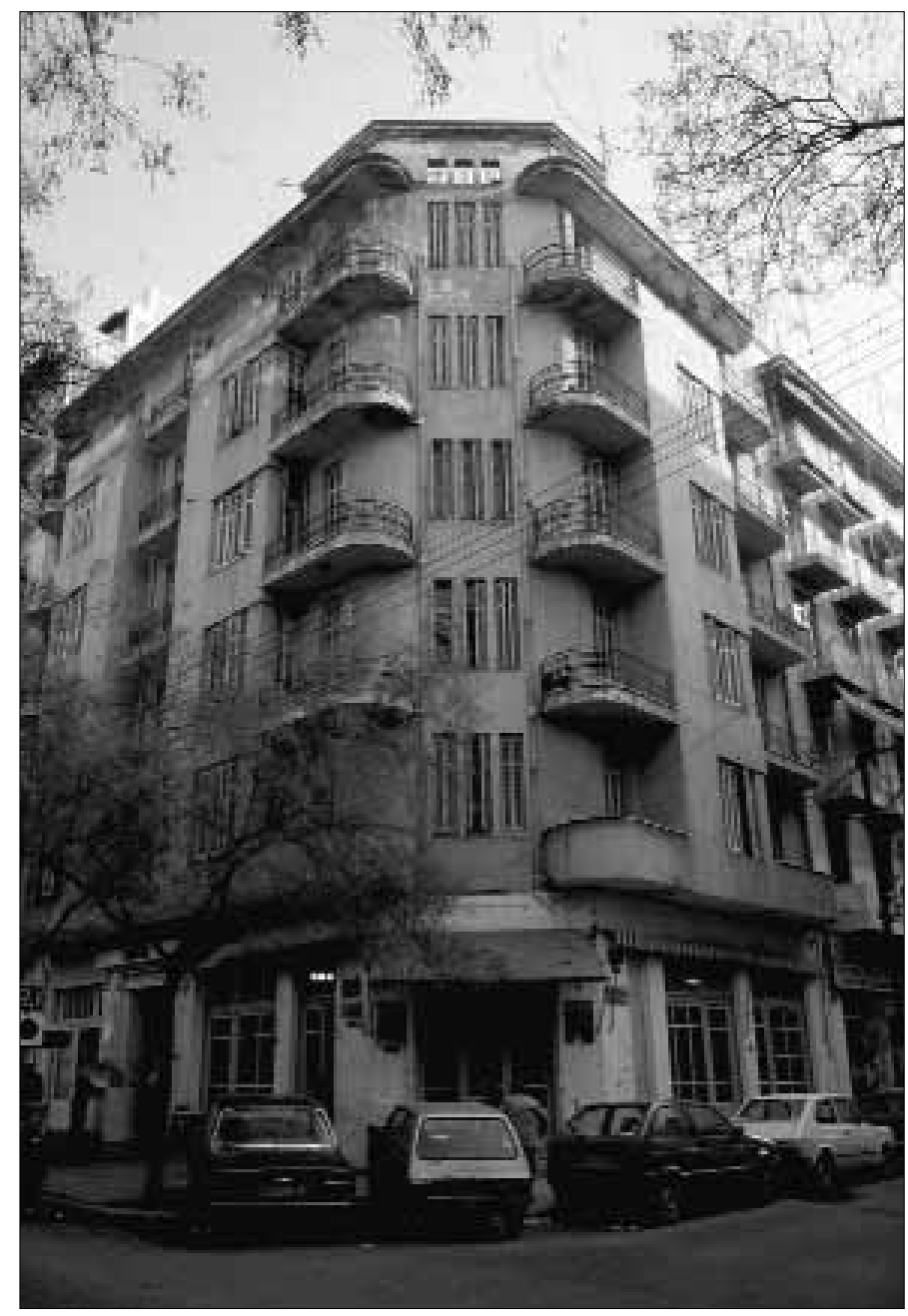




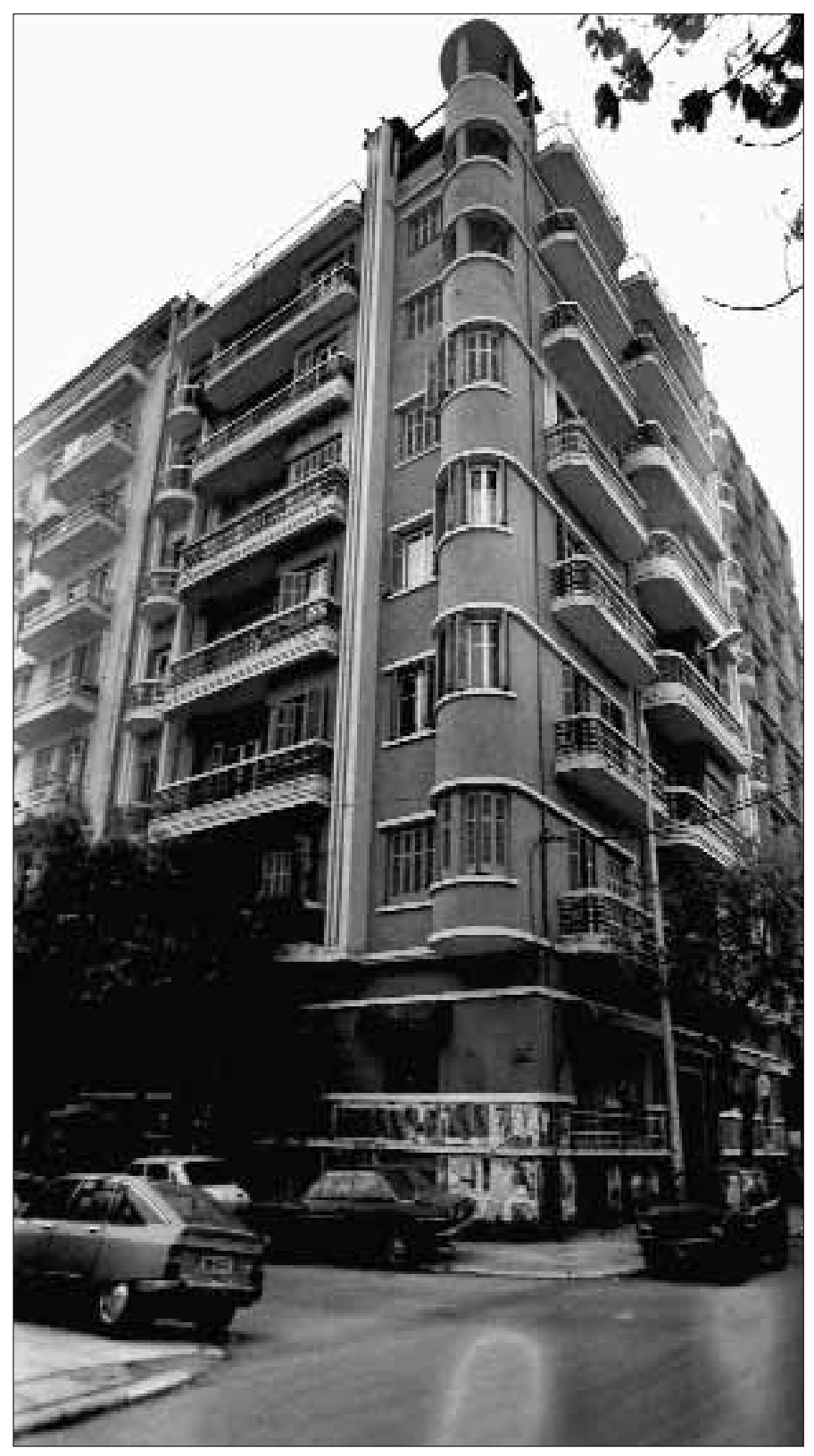

Fig. 22. Thessal oniki.

L'immeuble Guinis, rue M akenzie King (A. Tzonis -

L. Palaiologos, 1935). Photo deV. Colonas. 
Fig. 23. Thessaloniki. La nouvelle gare fer roviaire (Kleinschmidt-Jordan, 1939 \& T. Papagiannis - S. Molfessis, 1960). ArchiveV. Colonas.

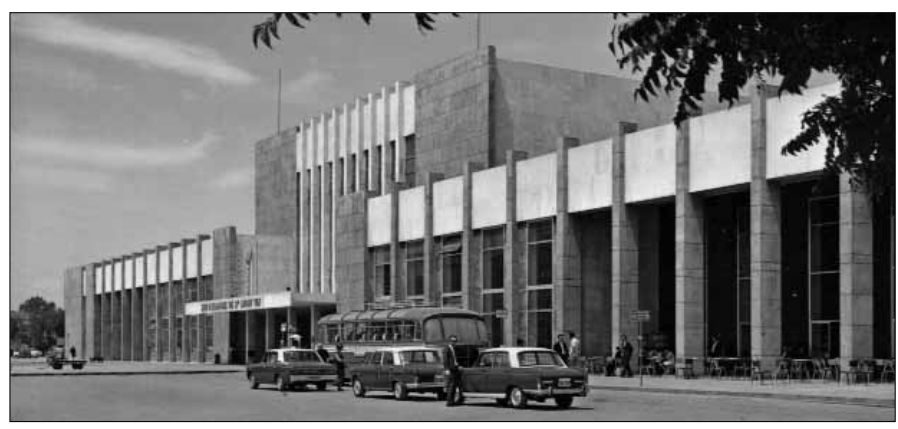

Fig. 24. Thessaloniki. La residence Saltiel dans I' ancien quartier des $C$ ampagnes (L. Zoidis, 1937). Photo de V. Colonas.

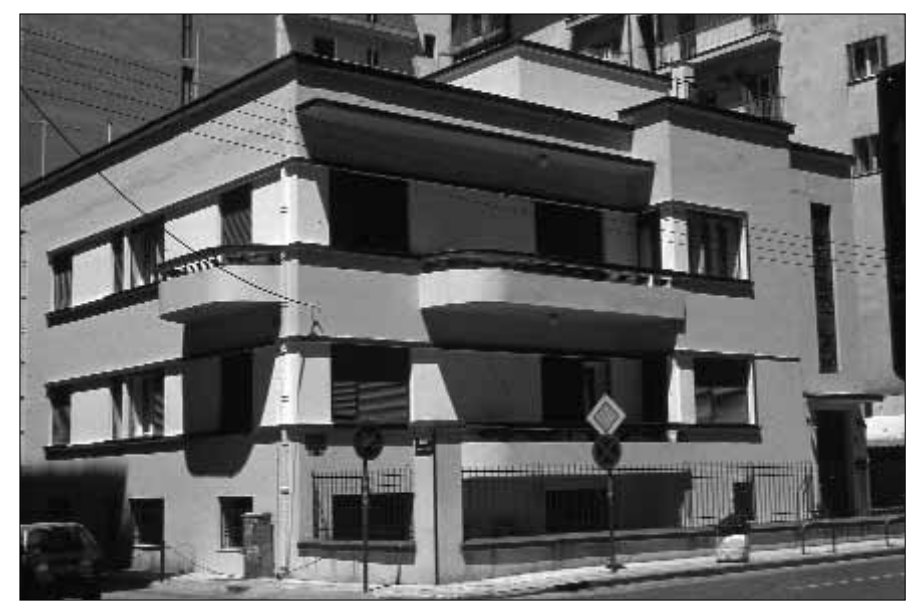

